\title{
Why the Standard TFR gives a Misleading Impression of the Fertility of Foreign Women: Insights from Switzerland
}

\author{
Marion Burkimsher, Clémentine Rossier, Philippe Wanner
}

\begin{abstract}
Since 1971 the Swiss Federal Statistical Office has published annual fertility data split by nationality (Swiss/foreign). These indicate that the TFR for women of foreign nationality has been 0.5 children higher than for Swiss women for most of the period since 1991. However, statistics from household registration (STATPOP) and the Families and Generations Surveys (FGS) in 2013 and 2018 indicate that foreign women, approaching the end of their reproductive lives, have slightly smaller families than women of Swiss nationality. The purpose of this paper is to reconcile these contradictory fertility measures. To do this, we design a novel methodology for tallying the fertility of cohorts of Swiss and foreign nationals through their reproductive life. In addition to birth registrations and population totals by age (the input data for calculating the TFR) we also include estimates of how many children women have at the time of their immigration, emigration and naturalisation. Using these input data, we compile the fertility profiles of Swiss and foreign women aged 15-49 (cohorts 1966-2003). These correspond well with the FGS and household register data.

Several processes impact the final fertility of the two sub-populations. Women frequently immigrate into Switzerland in their 20s. Often arriving childless, they commonly start childbearing soon after immigration. However, there is still a flow of low-fertility women into the country in their 30s and 40s, lowering the average fertility of the foreign population. By contrast, Swiss women start childbearing later and a significant proportion remain childless; however, after starting childbearing they have a higher propensity than foreign women to have a second and third child. Naturalisation and fertility are interlinked; women with children are more likely to naturalise than those without, which then boosts the average fertility of the Swiss population.

We confirm that the standard TFR gives an inflated impression of the ultimate (cohort) fertility of foreign nationals and under-estimates that of Swiss women, and we describe how this happens. Fundamentally, the TFR is a measure of childbearing intensity, not an accurate estimate of completed cohort fertility, especially for a mobile population.
\end{abstract}

Keywords: Immigrant fertility · Fertility of foreigners · TFR • Cohort fertility · Immigration · Timing of childbearing · Naturalisation · Postponement 


\section{Introduction}

The purpose of this paper is to address a conundrum. Whilst the period TFR of foreigners in Switzerland has consistently been higher than for Swiss nationals 0.5 children or more for most of the past three decades), the pattern is reversed from a cohort perspective: Swiss women have more children than foreign women by the time they reach their late $30 \mathrm{~s}$. We have confidence that both these measures are statistically robust, so how can the disparity between the period and cohort measures be reconciled?

The methodology presented in this paper quantifies the processes - births, in- and out-migration and naturalisation - that determine the fertility of cohorts of women as they pass through their reproductive lives. The results of our analysis come very close to the cohort fertility observed in household register data and two recent fertility surveys. Switzerland is a valuable case study because it has a large foreign population as well as excellent data sources.

The structure of the paper is as follows. The literature review focuses on studies that have addressed the weaknesses in the TFR when used for non-native groups. The unique characteristics of Switzerland and its evolving immigrant groups are then summarised, followed by a summary of the data sets used. We then describe the methodology used to tally the fertility of cohorts as they pass through their reproductive life. The elements of the calculation are discussed in more detail: births, immigration, emigration and naturalisation. We then compare the results of our cohort tracking with the fertility measures found in the household register and Family and Generations Surveys. Next, we summarise the processes which influence cohort fertility and address the fundamental weaknesses of the TFR and why it frequently does not indicate the ultimate number of children of foreign nationals. We conclude by discussing our results in the context of previous studies and make suggestions for which measures might better portray the fertility of native and non-native women.

Before launching into the body of the paper, we first need to clarify the definition and characteristics of our population subgroups.

- Swiss national (or simply "Swiss"): someone who holds Swiss citizenship, either from having had at least one Swiss parent or having naturalised. This may be in addition to other nationalities, as becoming Swiss does not automatically (nowadays) preclude holding other nationalities.

- Foreign national: someone with citizenship(s) not including Swiss nationality.

- Immigrant: anyone, of any age, arriving from abroad to live in Switzerland. They may have lived in Switzerland previously or even been born there, and may or may not have Swiss nationality.

The focus of this paper is the dichotomy between Swiss and foreign nationals, as this is the main classification used by the Swiss Federal Statistical Office (SFSO). However, there are several subsets within these two large groups:

1. Swiss born in Switzerland ("Swiss born $\mathrm{CH}^{\prime}$ for short). The majority of these women were Swiss from birth; however, a small proportion were born to 
parents with foreign nationality, so did not have the right to Swiss nationality at birth but gained it later in life. In the 2000 census about 5 percent of women

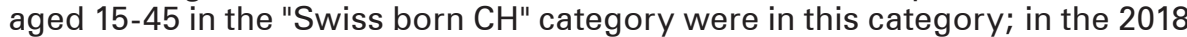
Family and Generations Survey (FGS) it was 9 percent.

2. Swiss born abroad. This group also has two components: Swiss from birth, having been born to at least one Swiss parent (whilst living abroad); and immigrants who came to the country as foreigners (as children or adults) and subsequently naturalised. At age 15 half of this group were Swiss from birth and half were naturalised; amongst women in their 40 s, 90 percent were naturalised.

3. Foreign national born in Switzerland ("Foreign born $\mathrm{CH}^{\prime \prime}$ ). Having been born to foreign parents, but then (often) having spent their childhood in Switzerland, women in this group tend to take up Swiss nationality in their "transition to adulthood" and "settling down" phase of life (and hence join group 1). As such, many in this group could be considered as "pre-naturalised". The rest may choose not to naturalise, either because they do not want to lose their existing nationality, or because they find the naturalisation process too daunting or expensive.

4. Foreign national born abroad. Some come to Switzerland as children with their parents, but the majority come as adults in their 20 s and 30 s.

Figure 1a shows these four sub-groups by age (15-49) in 2000 and 2018. In the period between these two years, the number of "Swiss born $\mathrm{CH}^{\text {" slightly declined }}$ in absolute terms (from $1.2 \mathrm{~m}$ to $1.1 \mathrm{~m}$ ), and the "Foreign born abroad" group rose significantly (from 20 percent to 28 percent of this age group). More than one-third of women in their 30s were "Foreign born abroad" in 2018. Figure 1b shows the proportion of women, Swiss and foreign, by whether they were born in Switzerland or born abroad, by age.

\section{$2 \quad$ Literature review}

In demographic literature there have been numerous studies comparing "native" and "non-native" fertility. These non-specific terms may refer to migration status (born in or outside the country of study), nationality (the focus of this paper) or ethnicity (which can include second- or higher-generation migrants).

This literature review focuses on specific aspects pertinent to our analysis: first, why the period TFR can be misleading when interpreted as lifetime (cohort) fertility; second, the timing of migration in relation to first birth and how this impacts the TFR measure; third, the duration of stay in the receiving country and its impact on the TFR; and fourth, the parity progression of migrants. Finally, we give an overview of alternative ways to describe the fertility of immigrants that may be better than the standard TFR. We return to discuss these in the final section of the paper.

The standard measure of fertility, the Total Fertility Rate (TFR), is a measure of the intensity of childbearing in a specific year (of the group of women in question); it only approximates ultimate fertility if the population (group) is stable, with no immigration, emigration, mortality or change in timing of childbearing. Sobotka and 
Fig. 1a: Population of women aged 15-49 in 2000 (left) and 2018 (right)

Population of women in 2000

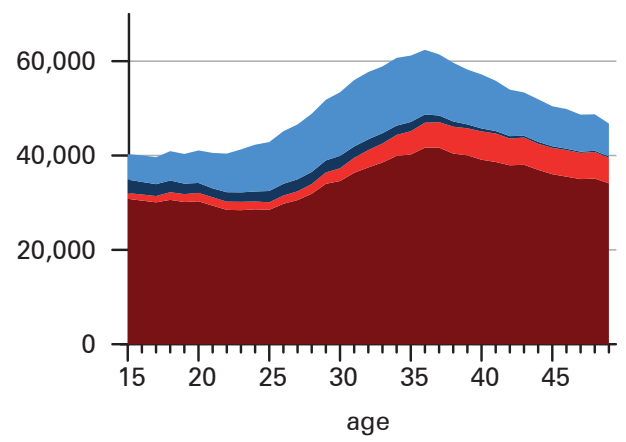

age

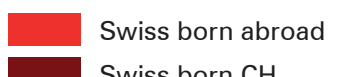

Swiss born $\mathrm{CH}$

the dashed line on right graph shows the cohort that was

15 years old in 2000
-1
Population of women in 2018

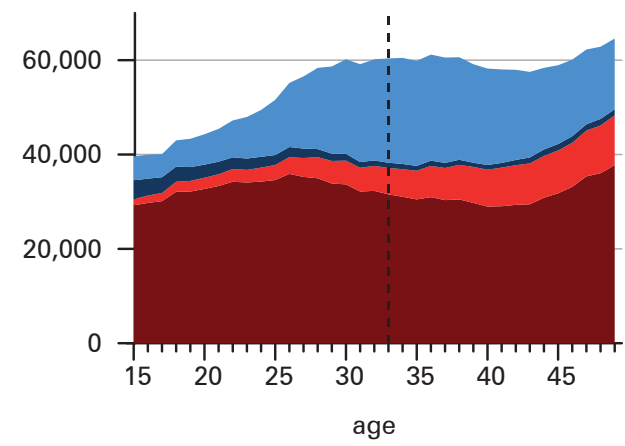

Foreign born abroad

Foreign born $\mathrm{CH}$

Fig. 1b: Proportion of women aged 15-49 born in Switzerland or abroad in 2018, Swiss nationals (left) and foreign nationals (right)

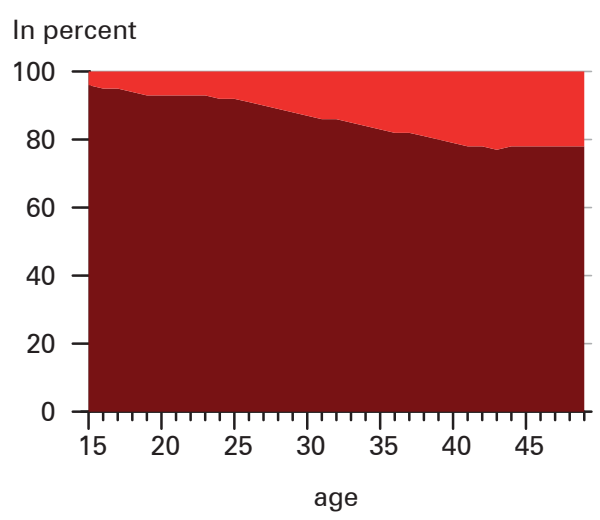

age

\section{Born abroad}

Born in Switzerland

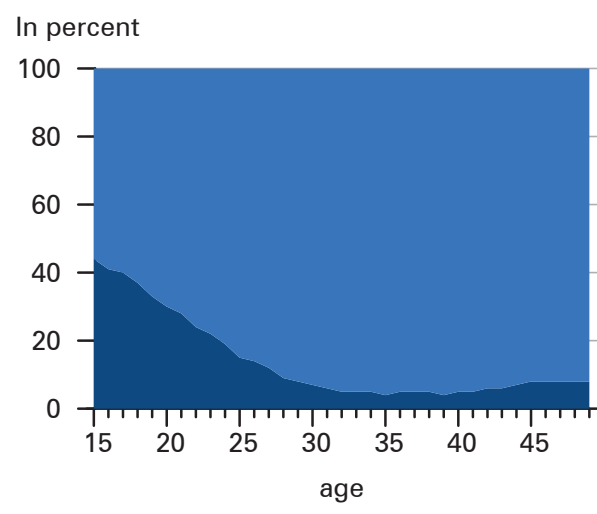

Born abroad

Born in Switzerland

Source: Census 2000, STATPOP 2018, Swiss Federal Statistical Office

Lutz (2010) heavily criticised its use because, although it is a simple measure, it often misrepresents cohort fertility and is easily misinterpreted by policy-makers. The distortions to the TFR caused by changes in timing of childbearing have been addressed extensively (the seminal paper on the deflationary effect of postponement is Bongaarts/Feeney 1998); however, the distortions inherent in calculating the TFR of non-natives have received less attention. 
The reason the TFR fails to characterise immigrant fertility is because there is, commonly, a high intensity of childbearing (often first births) in the years immediately after arrival in the new country following low fertility in the years preceding migration (Ng/Nault 1997; Toulemon/Mazuy 2004; Andersson 2004; Dubuc 2012; Robards/Berrington 2016; Tønnessen 2020). This has been termed a "migration-specific tempo effect" (Dubuc 2016). As outlined by Sobotka and Lutz (2010), the TFR for foreigners (as opposed to immigrants) is even more susceptible to distortion because women who stay longer in a country more often naturalise and are then no longer foreign nationals. Therefore, the TFR of foreigners tends to relate only to women who have been in the country for a relatively short duration after they arrive but before they naturalise, which is also a period of peak likelihood for starting a family.

In technical terms, a high intensity of first births inflates the TFR1 (first birth TFR) to values that can be higher than unity (one). In a stable population the complement of TFR1 (i.e. 1-TFR1) would be the proportion of women who remain childless; and so a value higher than one would make no sense in cohort terms. Parrado (2011), for instance, found values of TFR1 for immigrants to the United States from Mexico to be over 1.5 in the period 1990-2005. As the total fertility rate is the sum of fertility rates of all birth orders, then a "distorted" value for TFR1 will automatically lead to an unrealistically high overall TFR which does not reflect the "true" (cohort) fertility of immigrants.

Because migration and childbearing are often closely interlinked, the average duration of stay of immigrants in the new country has a significant impact on their TFR. The impact of change in average duration of stay, as well as other factors, has been analysed in detail to determine its relative importance on trends in the TFR of immigrants (Tønnessen 2020).

The likelihood and intensity of transition to second and third birth of non-natives have been the subject of several studies, with mixed results. In Germany, Milewski (2010) found immigrants transitioned to a second birth more frequently than native Germans, even if they had already had a child pre-migration. However, for third births, this only held true for immigrants from Turkey. In Switzerland the opposite was found: the transition to second birth for migrants was less frequent and came after a longer interval than for Swiss natives (Rojas et al. 2018). Berrington and Stone (2017) found that parity progression to third and fourth children is quite high in the United Kingdom for women from Pakistan and Bangladesh, although native British women also have higher proportions of three- and four-child families compared to many other European countries. In Italy migrants from Albania and Morocco are more likely to have a second or third child compared to Italian natives, but Ukrainian immigrants are less likely to do so (/mpicciatore et al. 2020).

What alternatives to the standard TFR to better describe migrant fertility have previously been proposed? Using data for France Toulemon and Mazuy (2004) applied three methods to the large data set of the 1999 survey Étude de l'Histoire Familiale: (1) an adjusted TFR, using estimated age-specific fertility rates which took into account the period of high childbearing soon after an immigrant arrives; (2) the "own children method" (Cho et al. 1986, Chapter VIII) which reconstructs, for years 
prior to the survey, the age-specific period fertility rates (ASFRs) and hence TFRs which include pre-migration fertility; and (3) a novel methodology combining data on the fertility of immigrants at the time they arrived in France (by age of arrival) plus their fertility in subsequent years. They concluded that "true" immigrant fertility was somewhat higher than native fertility but significantly less than the 0.7 excess implied by the standard TFR differential.

Using UK Labour Force Survey data, Dubuc (2009) compared two methodologies to describe fertility by ethnicity. She applied the child-woman ratio (CWR) and compared the results of this method with her refined reverse-survival own-child method, both methods including pre- and post-migration fertility for immigrant women. She found that the latter procedure, in particular, offers a reliable means of estimating fertility trends by ethnic and immigrant groups (Dubuc 2009, 2016).

Several other studies have also used the "own children method" to compare native and immigrant fertility (Krapf/Kreyenfeld 2015; Abbasi-Shavazi/McDonald 2002; Wanner 2002; Wanner/Fei 2005). The general conclusion is that (high-fertility) immigrant populations approach the (low-fertility) norms of the host country after a period of time.

To summarise, the standard TFR, by definition, only includes births to women already present in the country. Some studies (e.g. the ones cited in the previous three paragraphs) include pre-migration fertility histories in their estimates of ultimate (cohort) fertility. This adjusts the numerator (births) in the TFR calculation. Modifying the denominator (population of women aged 15-49) to include (commonly childless) migrants who have yet to arrive in the country has also been proposed as an alternative approach (Burkimsher/Rossier 2017).

All approaches to assess non-native fertility are constrained by the availability of reliable data; birth registration (by nationality or country of birth) data are generally available (in many developed countries) and it is a priori assumed that these can give estimates of the relative fertility of native and non-native groups. However, neither the fertility of arriving migrants nor the distortions inherent in the migrationspecific tempo effect are commonly taken into account - and the impact on the TFR of the fertility of emigrants has never, to our knowledge, been integrated into fertility models (although Toulemon/Mazuy 2004 acknowledged this deficiency).

\section{The Swiss context}

Switzerland has one of the highest shares of foreigners in its population amongst European countries. It also has a history of compiling high-quality demographic statistics (Calot 1998). Over one quarter of the 2019 permanent resident population of 8.5 million are non-Swiss; only Luxembourg and Liechtenstein have a higher percentage (Eurostat 2020). From being a poor country with predominantly negative net migration through the $19^{\text {th }}$ century and until 1930, Switzerland transformed itself into a wealthy country with its population growing primarily from strong immigration (Calot 1998). 
Fig. 2: Foreign female population aged 20-39 by nationality, 1995-2018

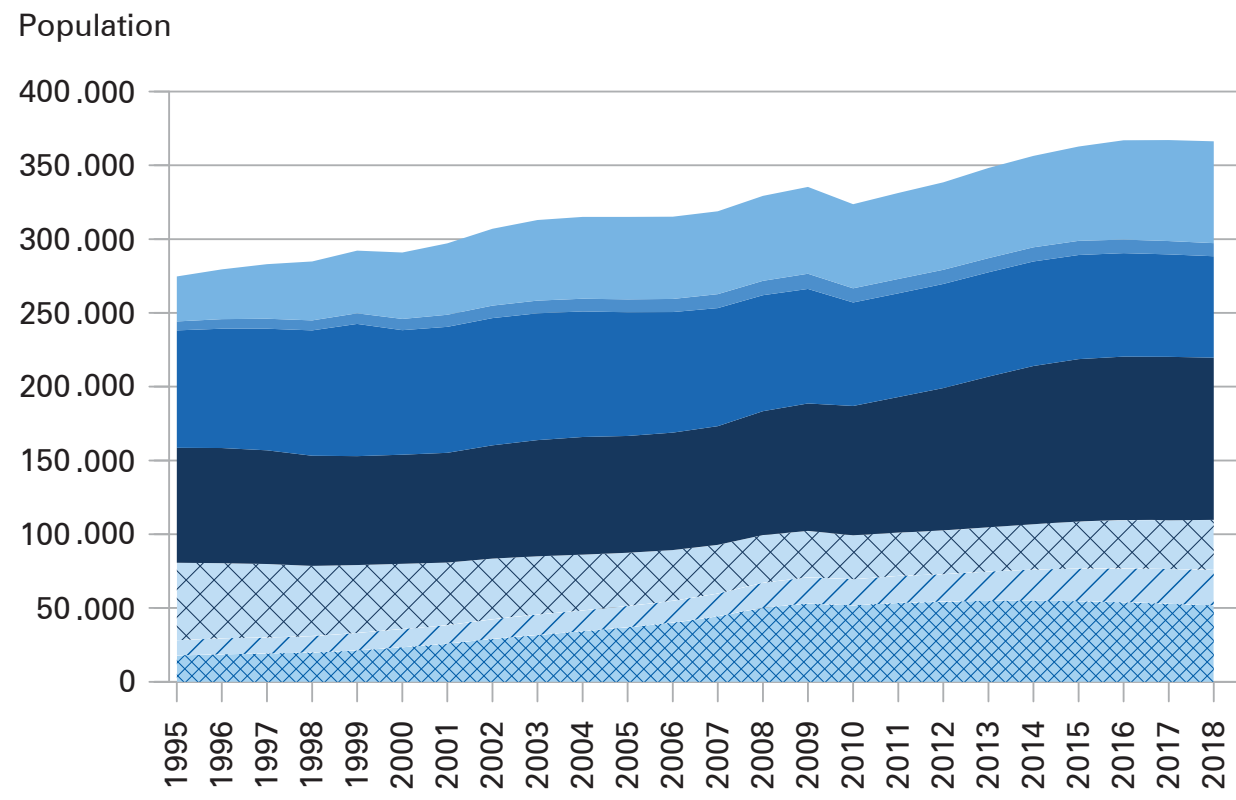

\begin{tabular}{ll}
\multicolumn{1}{c}{ year } \\
Non-Europe non-OECD & Italian \\
Non-Europe OECD & German \\
Other European & \\
Other EU and EFTA &
\end{tabular}

Other EU and EFTA: Austria, Belgium, Bulgaria, Croatia, Czech Republic, Denmark, Estonia, Finland, Greece, Hungary, Ireland, Latvia, Lithuania, Luxembourg, Netherlands, Norway, Poland, Portugal, Romania, Slovakia, Slovenia, Sweden, Spain, UK (and smaller countries)

Other European: Albania, Belarus, Bosnia, Kosovo, Moldova, Montenegro, North Macedonia, Russia, Serbia, Turkey, Ukraine

Non-European OECD: Australia, Canada, Chile, Japan, Mexico, New Zealand, South Korea, USA

Note: the kink from 2009-2010 reflects the change from the PETRA database to the household register system of collecting population data (STATPOP).

Source: PETRA and STATPOP

Prior to 1990 the main origin countries of immigrants were Italy, Spain and Portugal. The country has a long-standing culture of welcoming refugees, e.g. from Vietnam in the 1970s and Eritrea in recent years; in the 1990s it experienced an influx of migrants from former Yugoslavia. In December 2008 Switzerland joined the Schengen zone and, following that, more immigrants came from the new EU member states of Eastern European. In recent years the diversity of source countries has increased, with highly educated non-Europeans being a particular source of growth (D'Amato et al. 2019), a pattern seen elsewhere in Europe (e.g. the 
UK; Dubuc 2016). Currently, more Germans are arriving than have in the past, but fewer Italians. Figure 2 shows the evolution in the composition of the female foreign population of prime reproductive age (20-39) since 1995.

A number of studies on the fertility of sub-populations in Switzerland provide valuable background information for this study. Already cited are Calot (1998); Wanner (2002); Wanner/Fei (2005); Rojas et al. (2018) and D'Amato et al. (2019). A comparison of childlessness, using the 2000 census data, indicated that women from many Asian and Anglo-Saxon countries and Germany had higher rates than those born in Switzerland (of whom around 20 percent aged 40-70 were childless), whereas women from southern Europe and the Balkans were less likely to be childless (Burkimsher/Zeman 2017). Immigrants from France and Germany comprise a significant and growing share of new arrivals and have characteristic fertility patterns. These are reflected in the linguistic areas of Switzerland: Francophones enter motherhood earlier, whereas Germanophones more often remain childless - but, if they have one child, they move on to a second more readily (Ruckdeschel et al. 2018). The demography of foreigners in Switzerland is the topic of two edited volumes of papers: Wanner et al. (2012) includes chapters on fertility, naturalisation and emigration; Steiner and Wanner (2019) covers studies of "Migrants and Expats in Switzerland". The interconnected timing and propensity of life events of migrants (partnership, marriage, migration, birth of first and second child) compared to natives is investigated by Gerber and Burkimsher (forthcoming).

Extra-marital childbearing is relatively low but growing in Switzerland. In 2019 26 percent of births were outside marriage. Mixed marriages are very common. Since 2000, only a half or fewer of all marriages have been between two partners of Swiss nationality. In 201920 percent were between a Swiss man and a foreign woman and 16 percent between a foreign man and a Swiss woman. Of the 16 percent of marriages that were between two partners of foreign nationality, 45 percent were between partners of different nationalities. The analyses in this paper compare women primarily by nationality; however, we should remember that many of their partners have a different origin.

\section{Data sources}

We summarise here the data sources cited in this paper and discuss their applicability for our study. A critique of their weaknesses is covered in section 6 .

1. Census of December 2000. This was the last comprehensive decennial census; since 2010 population registers have been used to supply information on population numbers in a more timely and cost-effective manner. However, the 2000 census provides a wealth of additional information not available in population registers which has been exploited in this paper: the number of biological children and their years of birth (up to the $5^{\text {th }}$ or last); country of birth; nationality and (if applicable) year of naturalisation. However, it does not include the year an immigrant arrived in Switzerland.

2. Household register data (STATPOP) from 2010 onwards. This collates data on all households in Switzerland with information on the age, sex, nationality 
and country of birth of all co-residents (SFSO 2016a). When people move to Switzerland they are added to the register; when people leave they are recorded as emigrants. Annual data on immigrants, emigrants and naturalisations by age and gender are published. STATPOP superseded the PETRA database, which collated information about foreign residents up to 2009 (SFSO 2016b).

3. Birth registration by age and, from 1971, whether the mother had Swiss or foreign nationality (the BEVNAT database). Since 2011 births can be linked to the STATPOP database and so the country of birth of the mother can be retrieved. From 1971 onwards, the SFSO has published the TFR of Swiss and foreign women and, from 2011, by both nationality and country of birth.

4. Families and Generations Surveys (FGS) from 2013 and 2018 (SFSO 2013). These are two similar cross-sectional surveys sampled to be representative of the population of Switzerland; there are plans to repeat these every five years. Both surveys sampled almost 5000 women of reproductive age, over 20 percent of whom were foreign nationals. The FGS is similar in scope to the Generations and Gender Survey, which has been carried out in twenty other (mostly) European countries. Both FGS surveys include the year of immigration, but only the FGS 2013 includes the year of naturalisation.

5. Migration-Mobility Survey (NCCR on the move 2018). This survey sampled 7700 immigrants who had lived in Switzerland for less than ten years. This data set includes the country of residence of the children of migrants, Switzerland or abroad.

\section{$5 \quad$ Methodology}

The aim of our methodology is to estimate the average number of children of women by nationality (Swiss and foreign) as they pass through their reproductive life. As we have comprehensive data from 1981-2018 on the numbers of women immigrating, emigrating and naturalising, as well as their births, then we can track the full reproductive lives (ages 15-49) for cohorts born 1966-1969. For younger cohorts, we have estimates of their fertility over a shorter time span. In the example calculation described below, we have chosen to follow the cohort born in 1979, who reached age 39 in 2018. After this age, around 0.1 children may be expected to be added to their average fertility from additional births at current fertility rates.

Although we use the word "track", we do not have individual-level data for the number of children through the life course of women; rather, we make assumptions on average fertility (by age) at the transition points of immigration, emigration and naturalisation.

Tables $1 \mathrm{a}$ and $1 \mathrm{~b}$ show the elements and steps in the calculation for the 1979 cohort, who turned 15 in 1994. The mid-year population values are derived from the end-of-year population numbers as published by the SFSO (e.g. the mid-year population of 15-year-olds in 1994 is the average of the population of 14-year-olds at the end of 1993 and 15-year-olds at the end of 1994). The inputs of births and children associated with migration and naturalisation are described in sub-sections 5.1, 5.2 and 5.3. 
Marion Burkimsher, Clémentine Rossier, Philippe Wanner

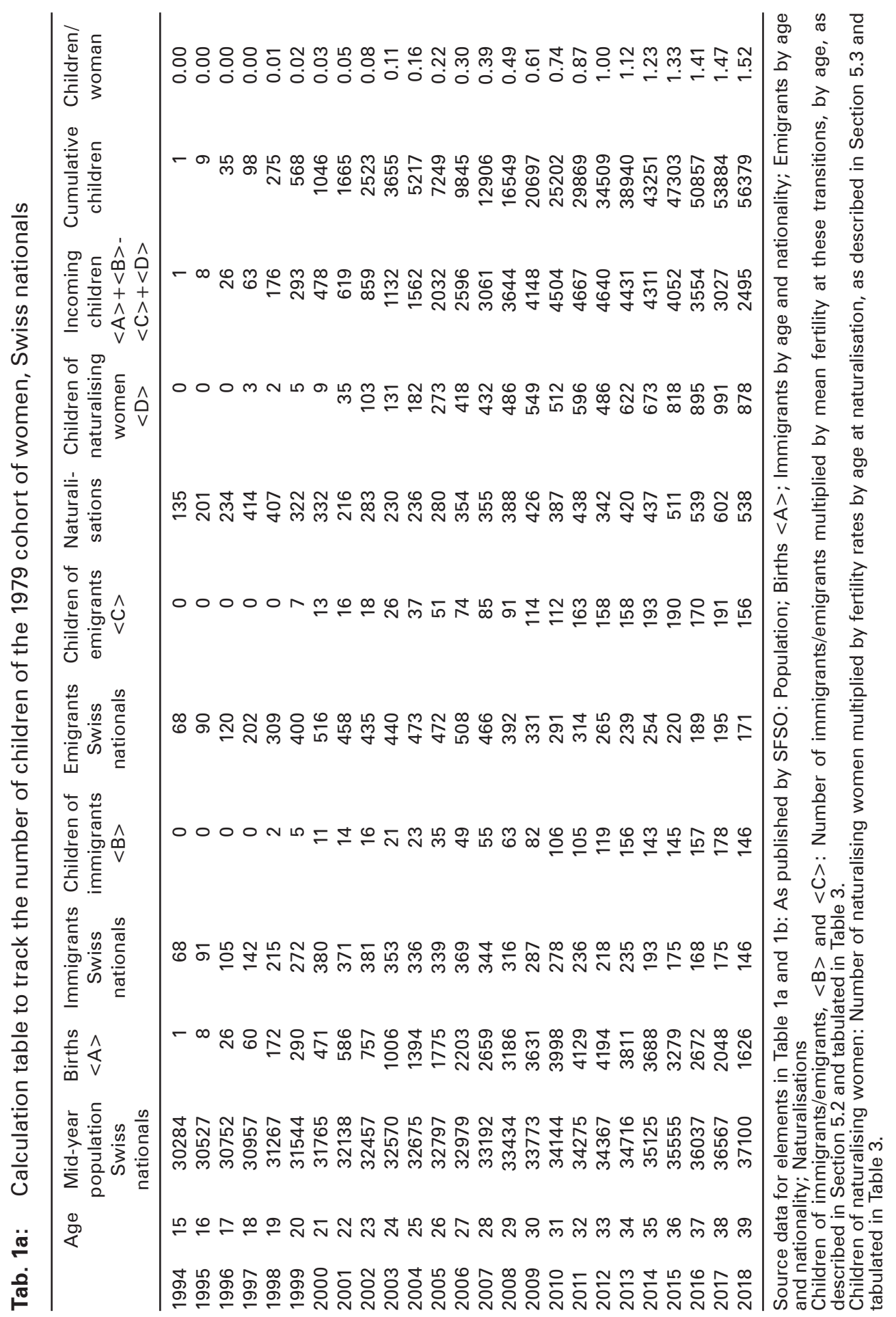




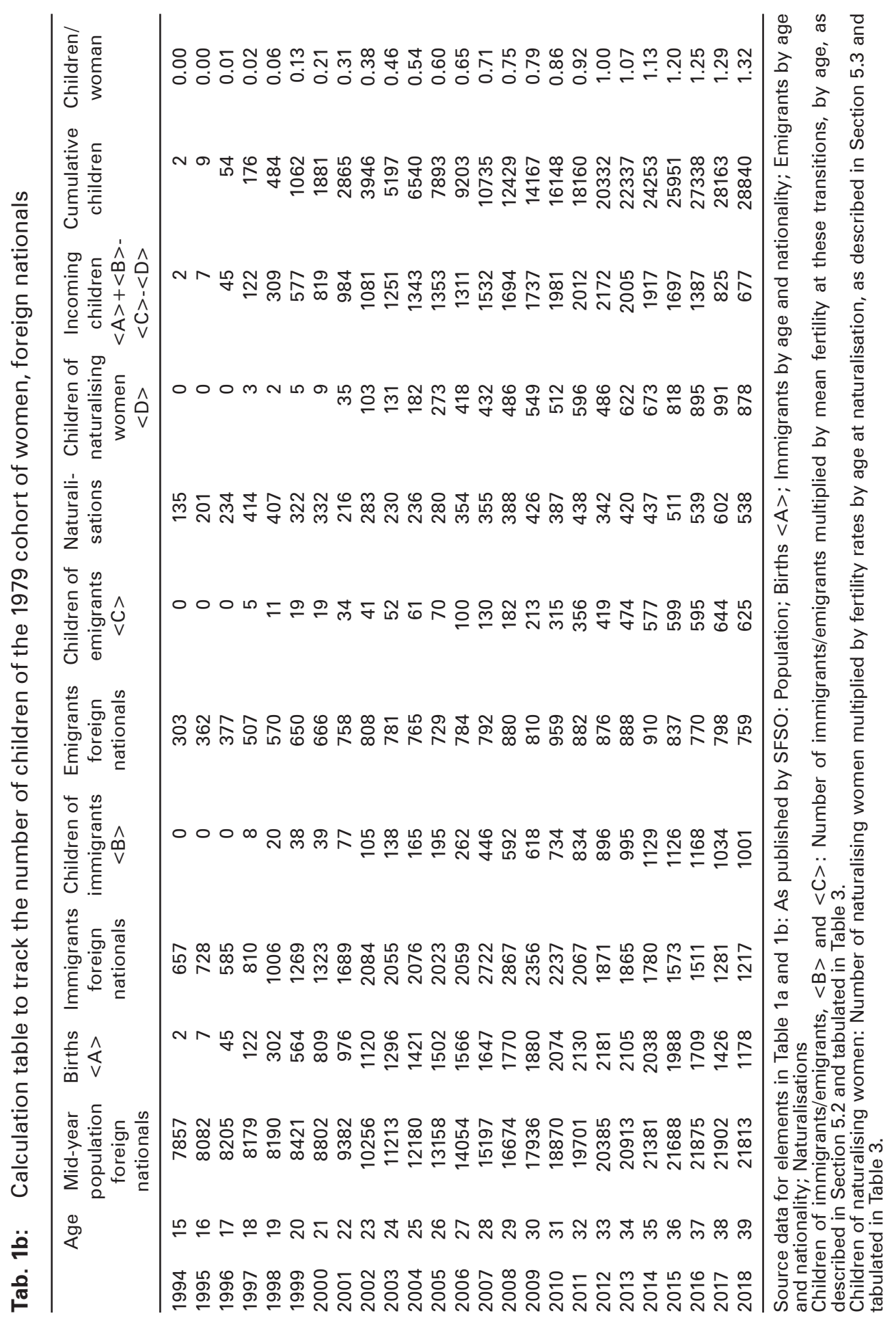


Fig. 3: The contribution of the 4 component elements to the fertility of Swiss and foreign women aged 39 in 2018, relative to the respective subpopulations

Children per woman

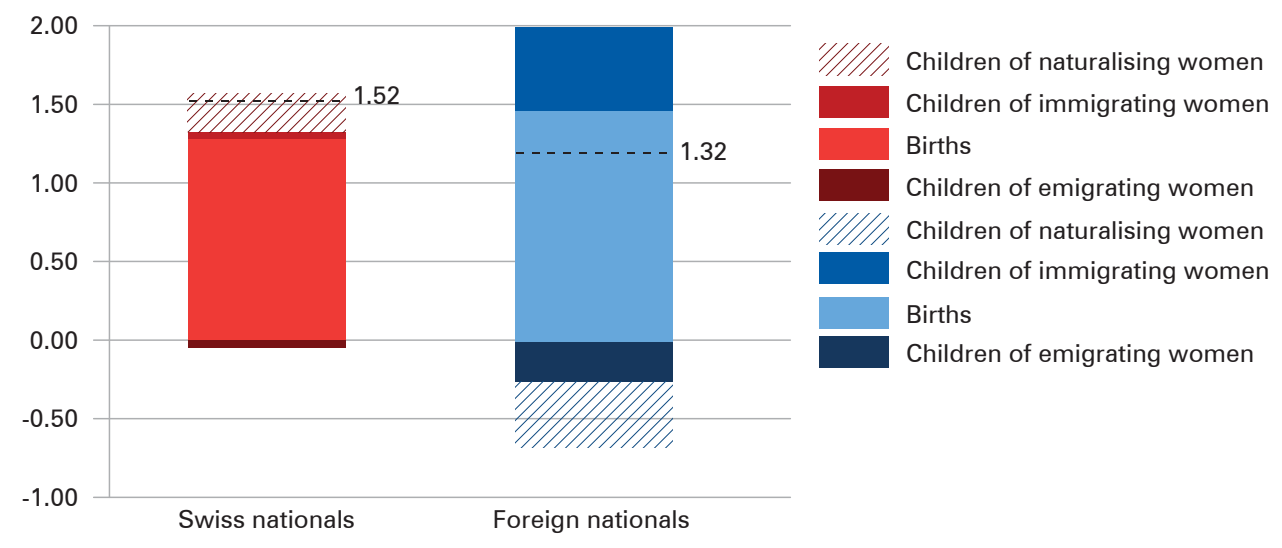

Source: see notes to Tables $1 \mathrm{a}$ and $1 \mathrm{~b}$

The cohort fertility calculation is straightforward. As shown in the final three columns of Tables $1 \mathrm{a}$ and $1 \mathrm{~b}$, we calculate the net number of children added from each source each year, and cumulate these. In the final column we divide the cumulated children by the female population in that year. This column is the fertility curve of the 1979 cohort, and the final number (bottom right of the table) is the estimated number of children for that cohort when they reached age 39 in 2018, i.e. their almost completed cohort fertility. Figure 3 demonstrates how the calculated fertility for that cohort at age 39 is compiled from the relative inputs and outputs of births, immigration, emigration and naturalisation.

How do these values for fertility through the reproductive period, calculated using our cohort tracking method, compare to the STATPOP values of co-residing children? STATPOP data are only available from 2011 onwards (so from age 32 upwards for our example cohort). A comparison of the results from the two data sets is shown in Figure 4. Three points should be highlighted. First, there is excellent agreement for the Swiss population up to age 35. At higher ages, we would expect the STATPOP values to under-estimate actual fertility as children will then start to leave home. The observed divergence is as expected. Second, STATPOP shows the fertility of foreign nationals to be about 0.07 children higher than the cohort tracking method at all ages. However, apart from this constant offset, the agreement is good (possible causes are discussed later in section 6). The third point to note is the crossover point between the fertility of Swiss women and foreign women. For STATPOP this is at age 34.5; with cohort tracking it is at 33. Analysing this phenomenon is one of the central aims of this paper and will be discussed at greater length in section 6; it is fundamental to understanding why the TFR inaccurately portrays the fertility of foreigners. 
Fig. 4: Average fertility of women born in 1979 from age 32 to 39 (2011-2018), Swiss and foreign nationals

Children per woman

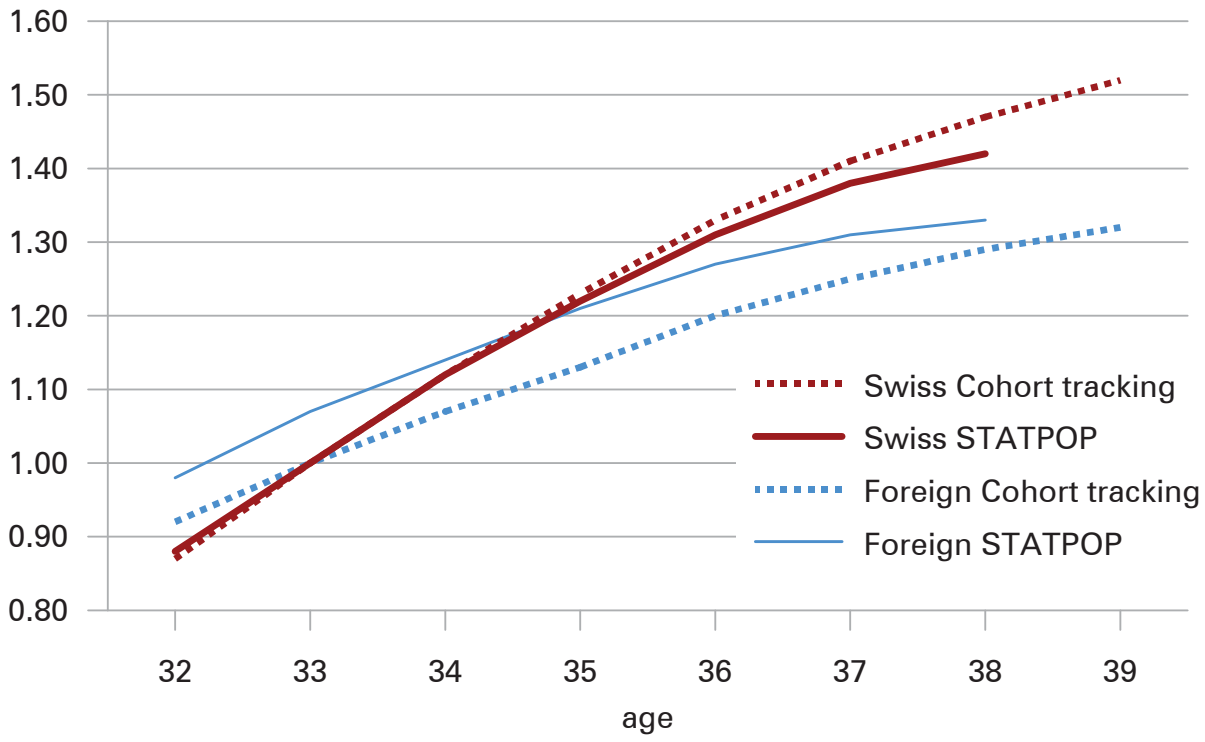

Source: STATPOP and Cohort Tracking methodology (see Appendix)

\subsection{Births by nationality and country of birth of mother}

The four sub-populations of Swiss and foreign women outlined in the Introduction contribute differing proportions to the total births in Switzerland. Births to women in the "Swiss born CH" category comprised 57 percent of total births in 2010, declining to 51 percent in 2018. Meanwhile the proportion to "Swiss born abroad" stayed quite steady at 8-9 percent. The proportion of births to women "Foreign born abroad" rose from 35 percent to 39 percent between 2010 and 2017 before falling slightly to

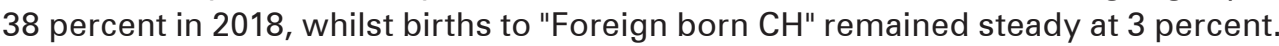

The four groups have different fertility behaviours, particularly in relation to timing, both age at first birth and subsequent spacing between births. Women who are "Foreign born abroad" become mothers youngest (see Fig. 5). By contrast,

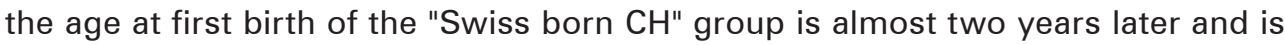
now approaching 31. The steady rise in mean age at first birth ("postponement") seen since 1970 finally seems to be slowing. The rather young age for "Swiss born abroad" (mostly naturalised immigrants), 28.5 rising to 29.5 , suggests that many of these women have either immigrated to Switzerland as children or married a Swiss man and thus had a fast-track route to citizenship (see section 5.3 on naturalisation). 
Fig. 5: $\quad$ Mean age at first birth by nationality and country of birth of mother Age at $1^{\text {st }}$ birth

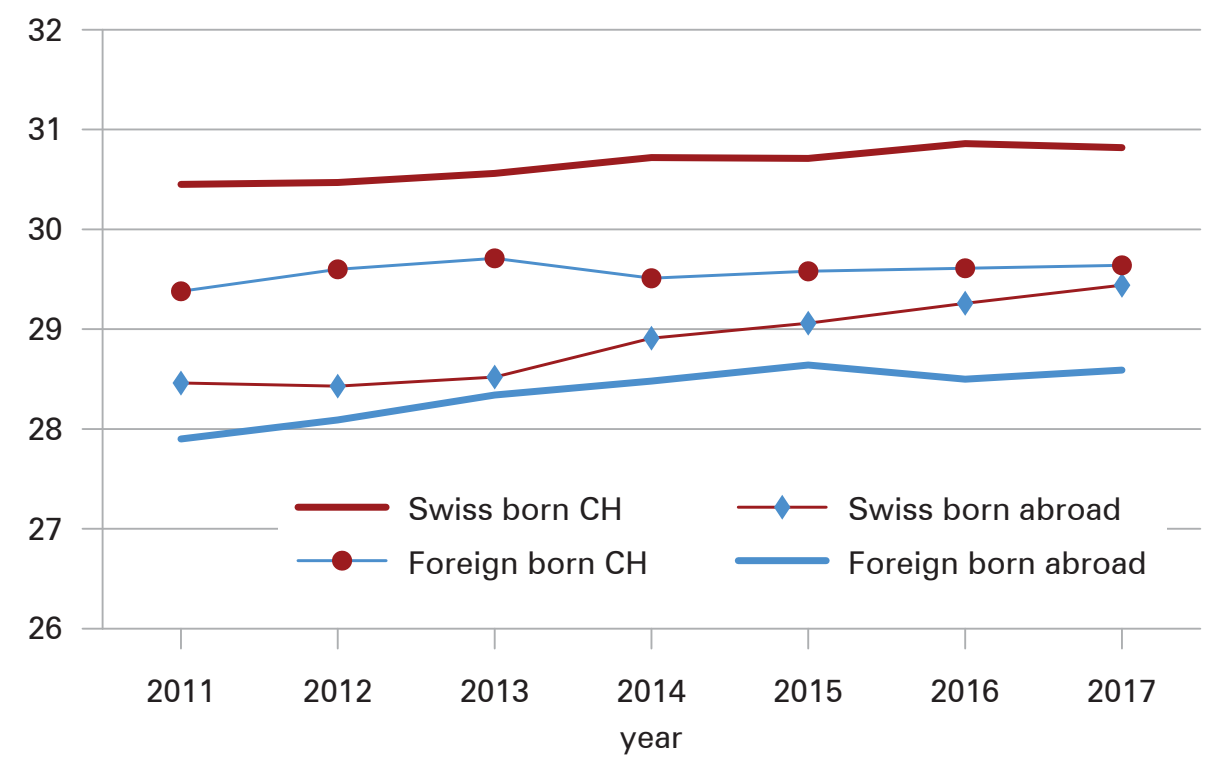

Source: own calculations using BEVNAT and STATPOP data

\subsection{Immigration, emigration and fertility rates at those transitions}

The main influx of foreign women into Switzerland starts at age 18 , often for tertiary education or low-skilled service jobs. This is followed by even stronger in-migration, often for work (for the woman, her partner or both), or joining a partner; this peaks at age 26. Strong immigration is partially balanced by emigration, which follows a similar age trajectory (see Fig. 6). For Swiss nationals their net balance is negative throughout the age range 15-49, with peak outflow at age 25 .

The household register, STATPOP, is our main data source on the number of children that women have when they immigrate or emigrate. For our cohort tracking calculations we used the average fertility rates by age from STATPOP for the years 2011-2017 (see Table 3). There were no noticeable trends over this period.

One weakness of the STATPOP data for estimating immigrant fertility is that the mother may arrive in the country before her children, or they may remain in the country of origin, especially if they are older, and this can lead to an under-estimate of the fertility of immigrating mothers. We know from the Migration-Mobility Survey (NCCR on the move 2018) that for women under 35, more than 90 percent of mothers arrive with their children; however, this drops to 85 percent for women aged 35-39, 70 percent for women 40-44, and just over half for women aged 45-49. We have used these values to apply a multiplicative coefficient to the STATPOP values to better estimate true fertility at immigration for foreign nationals (i.e. by multiplying the fertility rate calculated from STATPOP by the inverse of the proportions listed above). 
Fig. 6: Number of women immigrating and emigrating by age, mean 2011-2017

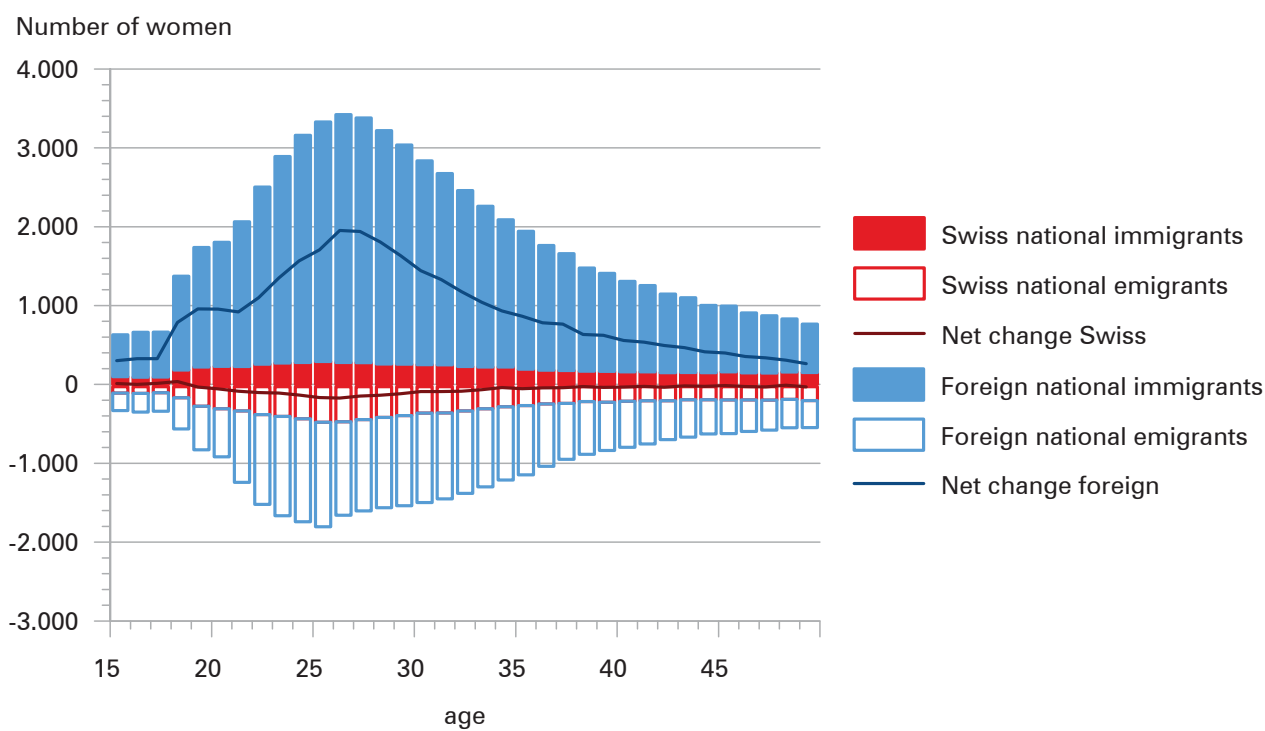

Source: STATPOP

Both the STATPOP data and the FGS of 2013 and 2018 show that the majority of migrants are, in fact, childless, whether they are arriving in or leaving the country (see Table 2).

As discussed in the literature review, entry into motherhood is commonly postponed before migration and then commences in the years shortly afterwards. We found this same behaviour with immigrants to Switzerland (see Fig. 7). We discuss the impact of this high post-arrival childbearing intensity on the TFR, and in particular on the TFR1, in section 8.

STATPOP enumerates not only the number of children of immigrants and emigrants but split by whether or not they (already) hold Swiss nationality. Of note is that the fertility of foreign nationals is slightly higher on emigration than it is on immigration, comparing women of the same age. The opposite is the case for Swiss nationals: their fertility is lower on emigration than on (re-)immigration.

\subsection{Naturalisation and fertility at naturalisation}

The methodology section showed that naturalisation potentially impacts the cohort fertility of Swiss and foreign nationals, as there is, effectively, a transfer of associated children from the "foreign" tally to the "Swiss" tally. In this section, we discuss the recent history of naturalisation legislation and how this links to family formation of women. We then describe how we estimate the fertility of women when they naturalise.

The SFSO publishes data for the number of men and women naturalising each year (see Fig. 8). Several important changes in the naturalisation rules have been 
Tab. 2: Proportion childless in year of immigration and emigration by age group

\begin{tabular}{|c|c|c|c|c|}
\hline & \multicolumn{3}{|c|}{ At immigration } & \multirow{3}{*}{$\begin{array}{l}\text { At emigration } \\
\text { STATPOP }\end{array}$} \\
\hline & FGS 2013 & FGS 2018 & STATPOP & \\
\hline & \multicolumn{3}{|c|}{ in \% } & \\
\hline $20-24$ & 93 & 93 & 96 & 97 \\
\hline $25-29$ & 87 & 81 & 90 & 89 \\
\hline $30-34$ & 82 & 41 & 75 & 70 \\
\hline $35-39$ & 51 & 13 & 60 & 53 \\
\hline
\end{tabular}

Note: the FGS 2018 under-sampled childless women and even applying appropriate weights does not fully compensate for this bias.

Source: FGS: women who immigrated in the previous ten years; STATPOP, mean 2011-2017

Fig. 7: Timing of first birth with respect to year of immigration: percent by year who had a child within 10 years of immigrating

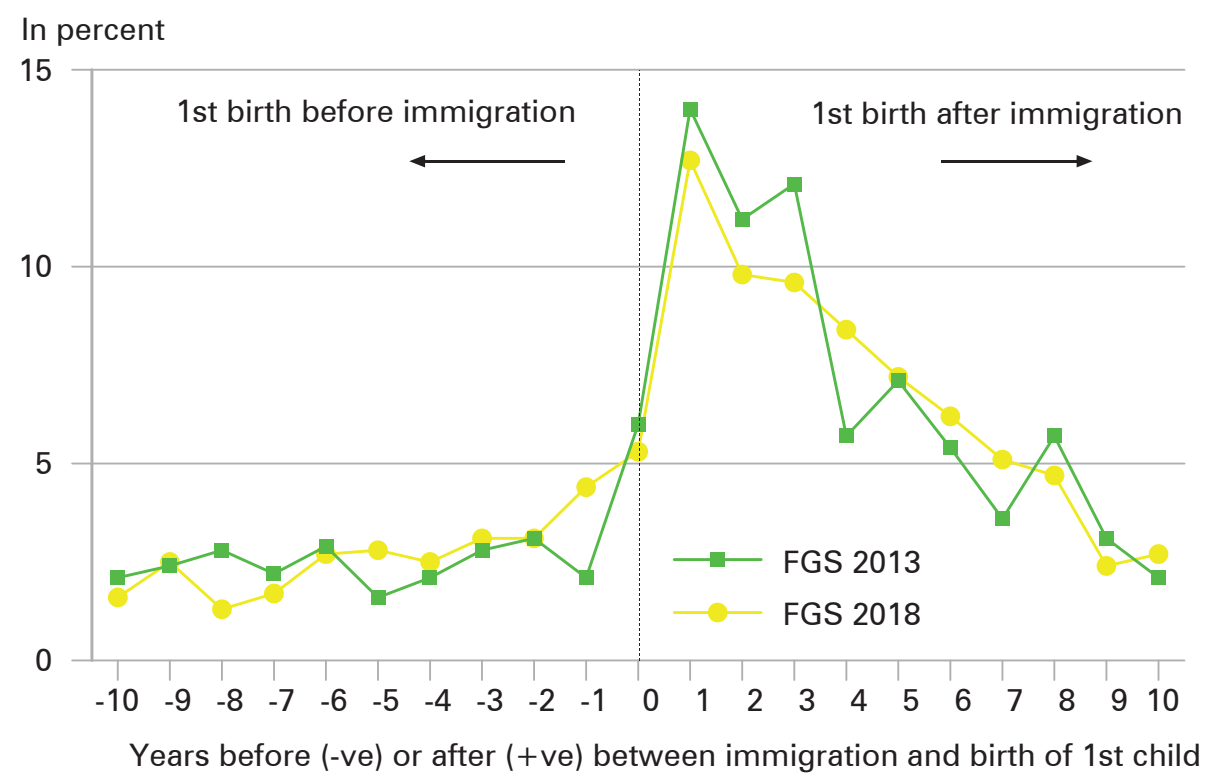

Source: FGS 2013 and FGS 2018, women who immigrated to Switzerland over the age of 15 and aged $<=49$

made over the past decades. In the 1970s, women who had lost their Swiss citizenship (because of marrying a non-Swiss man, for instance) could regain it on request. Up until the end of 1991, a foreign woman who married a Swiss man automatically gained Swiss nationality (and may thereby have lost her existing nationality); this statute was dropped with the introduction of a new law on citizenship. A foreign woman marrying a Swiss man (and vice versa) can now apply for fast-track citizenship, although this still takes several years (Swiss/nfo 2018). Years spent in 
Fig. 8: Descriptive diagrams of naturalisation trends 8a: Number of women naturalising by age group, 1981-2018

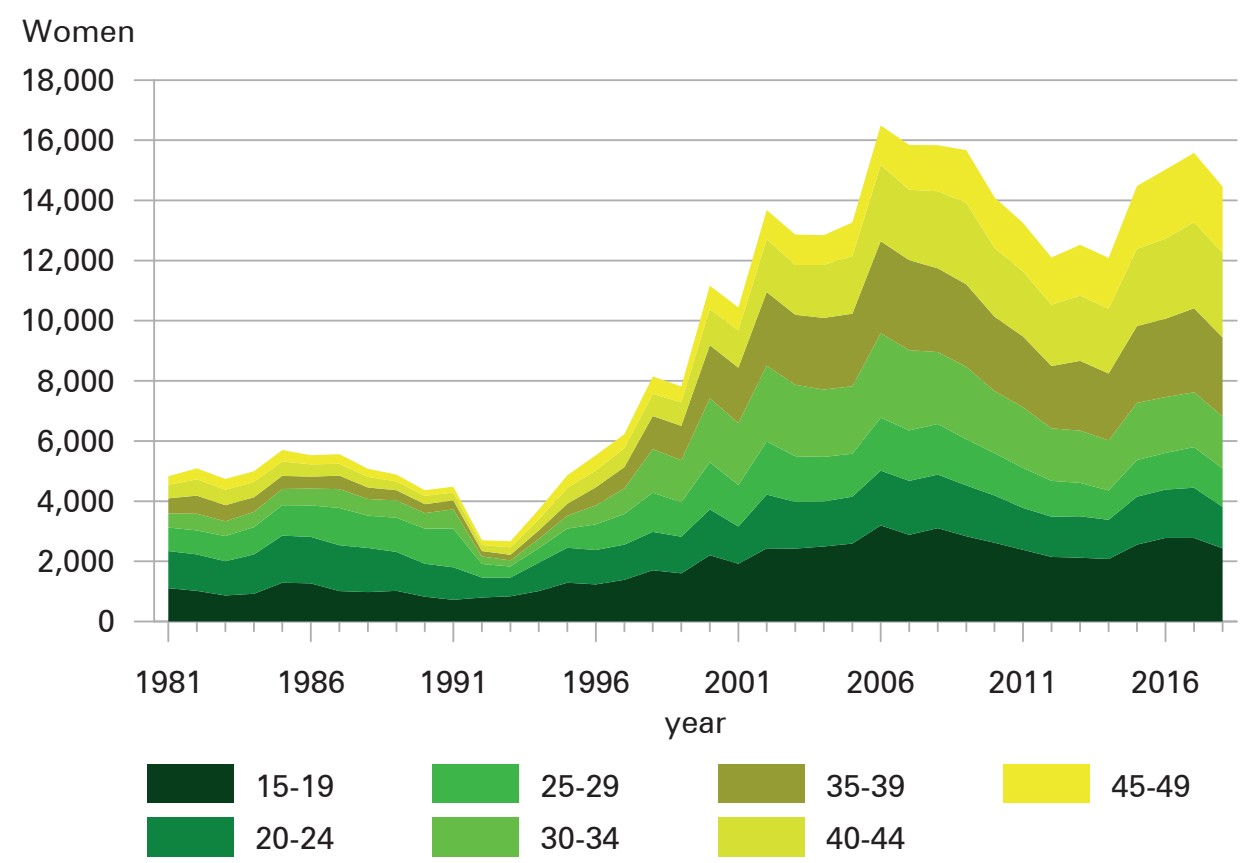

8b: Annual naturalisation rates of women by age (number of naturalisations/foreign population), selected years

In percent

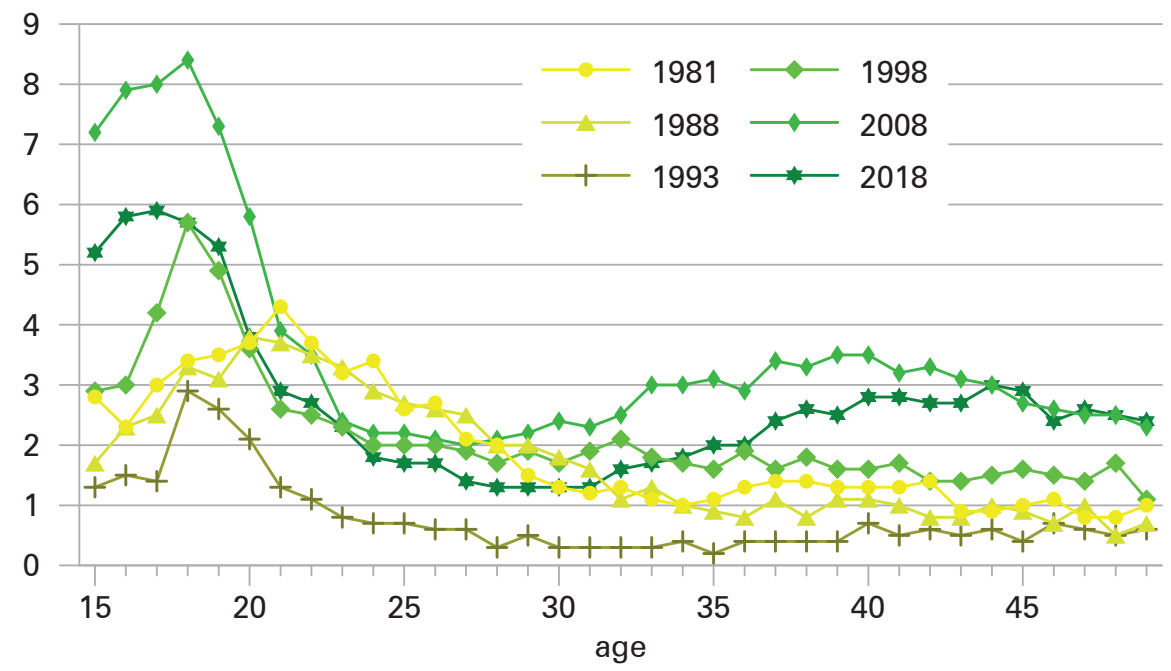

Source: SFSO 
Switzerland in childhood count double towards gaining citizenship. The duration of time living in the country before being able to obtain citizenship by the standard route was reduced from twelve years to ten in January 2018 (SEM 2018). One of the countries which, until recently, allowed only single citizenship was Germany; however, since 2007, German women can hold dual citizenship of Switzerland and Germany, and many older German women living in Switzerland have chosen to do so (Swiss/nfo 2007).

Naturalisation has traditionally been part of the transition to adulthood and this remains the case for many children who were born or have spent most of their childhood in Switzerland: the peak around age 18 is very marked (Fig. 8b) and at this age almost all are childless. Naturalisation and fertility are interlinked, as described in Pecoraro (2012). To summarise, women with children commonly choose to naturalise when their duration of stay is long enough, whilst childless women have a slightly lower propensity to naturalise than mothers.

We used two data sources to estimate the number of children that women have (on average, by age) at the time of their naturalisation. The 2000 census data includes the year of naturalisation, as well as the years of birth of all children. From this we can calculate the number of children a woman had in the year she naturalised. For the pre-census years 1981-2000, we averaged the fertility at naturalisation for four periods, with 1992 being a special year for the reason described above (see Table 3). For the years after 2000 we used the FGS 2013 to calculate fertility at naturalisation; 347 women in the survey had become Swiss since 2000 in their reproductive period (15-49). Fertility at naturalisation is higher at all ages than fertility at immigration or emigration for the reasons described above. Fertility at naturalisation has been rising over time, the main reason being that since 1991 women do not gain Swiss citizenship on marrying a Swiss man; they must wait at least six years, even when fast-tracked.

\section{Comparison of cohort fertility measures from different data sets}

The purpose of the methodology described in section 5 is to calculate the average fertility of co-existing cohorts - of Swiss and foreign nationals - which can be compared with values obtained from other sources (census 2000, STATPOP, FGS 2013 and FGS 2018). The significance of our methodology is that we understand the source of the inputs (births, immigration, emigration and naturalisation) whereas with other data sources we can only observe the differentials. This section presents the data and discusses the weaknesses of each data source. In the subsequent section, we summarise the processes that determine cohort fertility patterns of Swiss and foreign nationals and then address the question of why the pattern we see in cohort fertility differentials is fundamentally different from that seen in the TFR.

Figure 9 shows the fertility of co-existing cohorts in the years when the census or survey was carried out. For the cohort tracking method the graph plotted is for the latest year for which we can calculate, 2018 (see the data tables in the Appendix). 


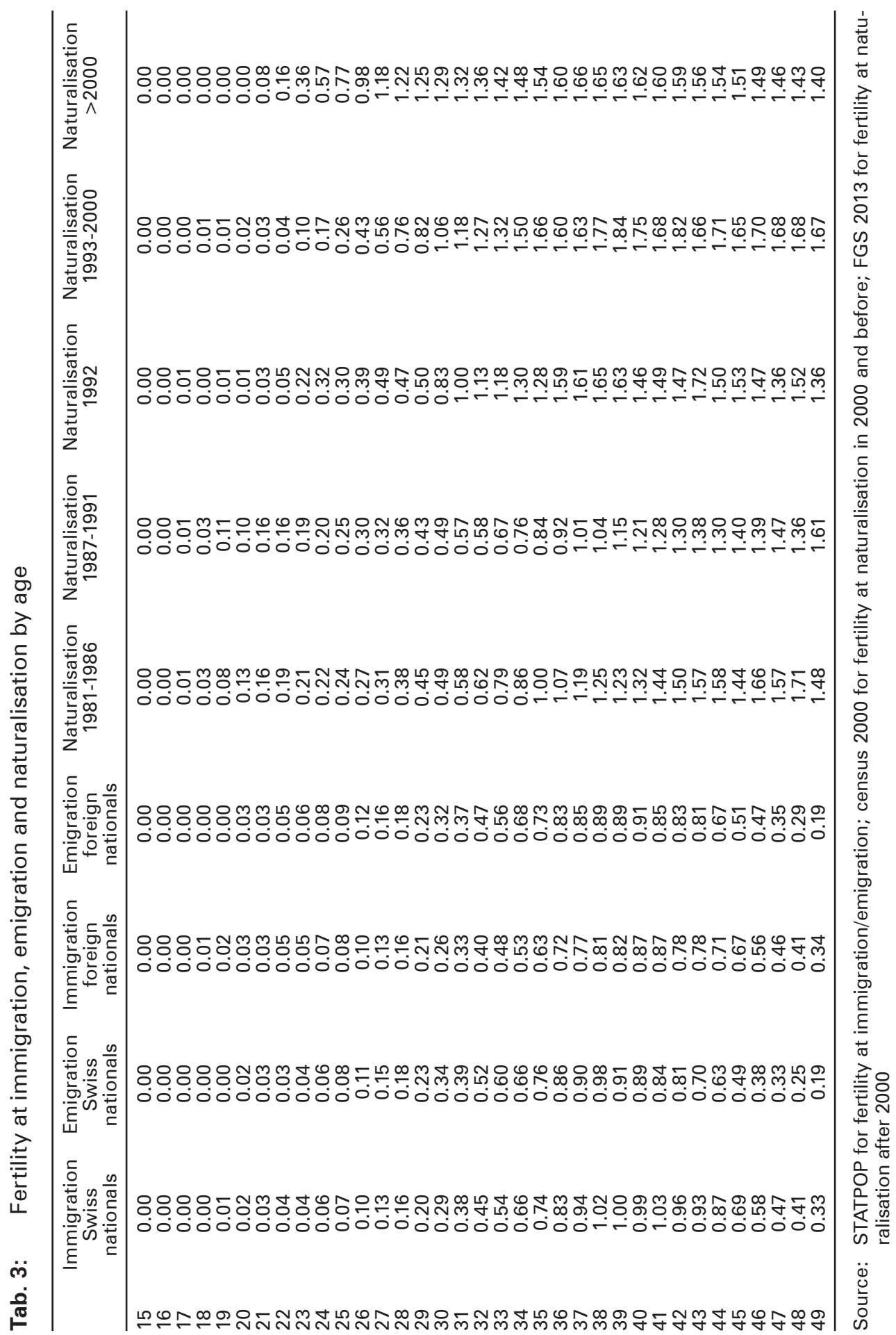


Fig. 9: Cohort fertility of female Swiss (red, bold line) and foreign nationals (turquoise, lighter) aged 20-49 in year(s) of observation

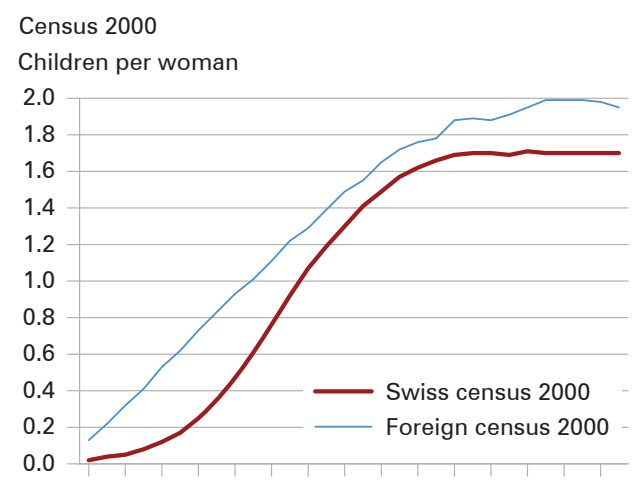

202224262830323436384042444648

age

FGS 2013 5-year rolling averages

Children per woman

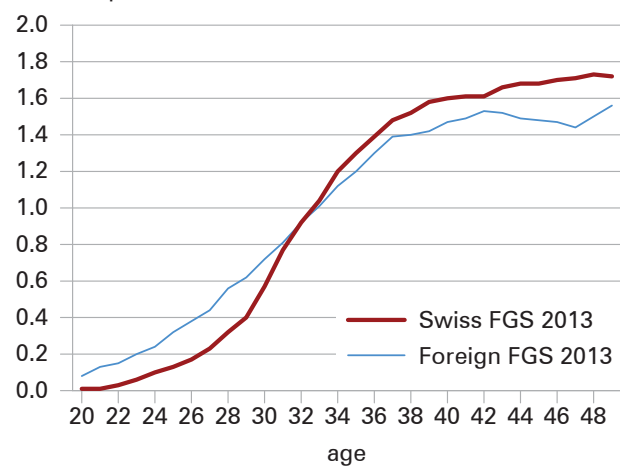

Cohort tracking methodology 2018

Children per woman

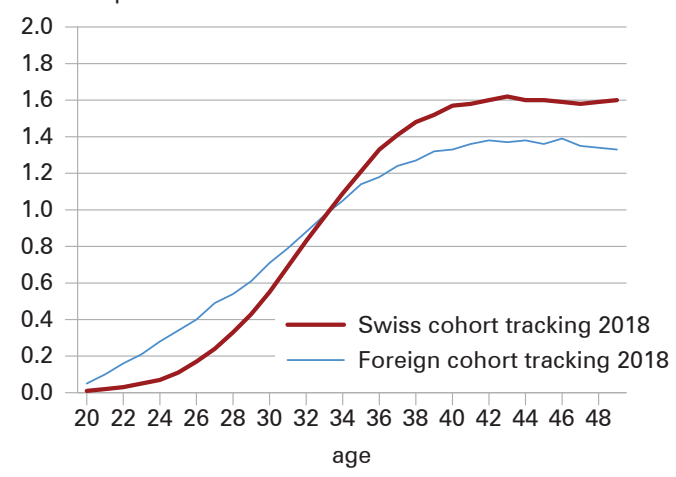

Source: own calculations based on sources as listed
STATPOP, mean 2011-2017

Children per woman

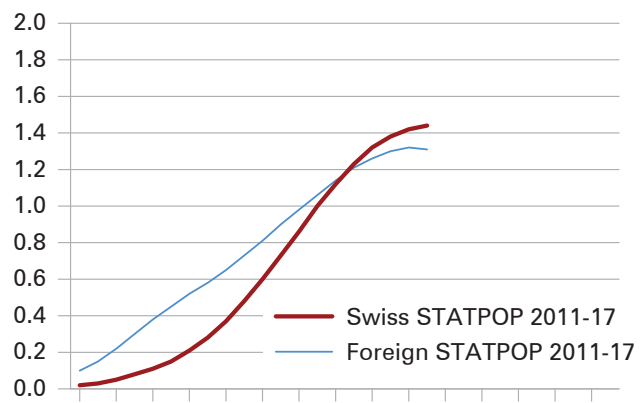

202224262830323436384042444648

$$
\text { age }
$$

FGS 2018 5-year rolling averages Children per woman

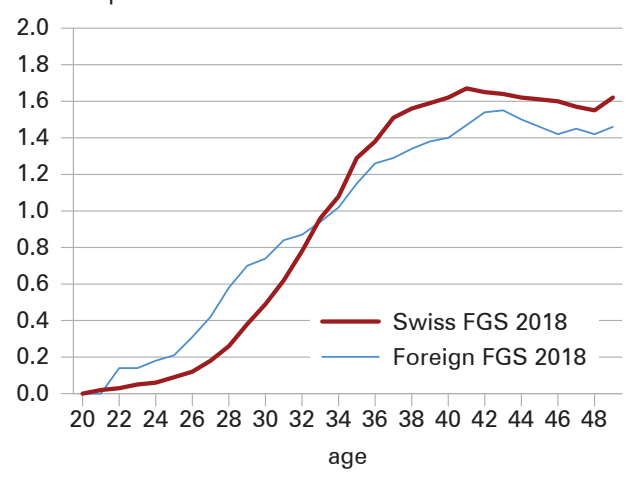


The first point to note is that there appears to have been a change in the Swissforeign differential between the census in 2000 and 2011. In 2000, foreign women had higher fertility across all the reproductive ages compared to Swiss nationals. However, since 2011, the four different data sources all point to the same conclusion: women of Swiss nationality past their mid-30s have higher fertility than women of foreign nationality. The values for completed cohort fertility differ between the data sets, yet they all show this same crossover. For STATPOP the crossover occurs at age 35; with the FGS 2013 and FGS 2018 it is at age 33; and with our cohort tracking for 2018 it is at age 34 .

The second point to note is that the comparability between our cohort tracking results and STATPOP is particularly close, which gives us confidence in our calculation process. It should be noted that the mean fertility by age was calculated for years 2011-2017 for the STATPOP values. No trends were discernible over that period for the fertility of Swiss nationals nor of foreign women.

We now discuss each data set in turn. The census data are almost comprehensive, although 4.5 percent of Swiss women and 8.9 percent of foreign women aged 20$39 \mathrm{did}$ not respond to the question on their number of children. However, these data are now twenty years old; no comparable data set has been compiled since. It is interesting to note the convergence in the Swiss-foreign fertility differentials between the ages of 35 and 39 in 2000. It would appear that although completed cohort fertility (CCF) of Swiss nationals has fallen only slightly since then, from 1.7 to 1.6 , the CCF of foreign nationals has fallen much more steeply. It should be noted that in the 1990s there was an influx of migrants driven by the wars in the Balkans, first Serbians and Croatians in the early 1990s, followed by Kosovars in 1998/99. Since then there has been an increase in the proportion of migrants who are highly skilled, as well as (and including) Germans, both groups who tend to have lower fertility (see section 3 and Fig. 2).

The main weakness of the STATPOP values is that they take into account only children who are co-habiting with their mother. Analysis is by household: if a household includes a female aged 20-39, then any child(ren) 15 or more years younger than her are considered to be hers. In Germany a similar analytical method to ours was used with their Mikrozensus: it was found that up to their late $30 \mathrm{~s}$ the fertility of women assessed by co-residential children was very close to that reported by women on their biological children (Krapf/Kreyenfeld 2015). For this reason, we only include women up to age 39 . Foreign women are more likely to have their children leave soon after age 40 as, on average, they start childbearing at a younger age than Swiss women do (Fig. 5). There is a sharp increase in emigration from age 18 (of both Swiss and foreign nationals), many of them leaving the parental home for higher education. The FGS 2013 data shows that 46 percent of women in their 40s and who immigrated at age 15 or above had an eldest child aged 18+; this compares to only 39 percent of Swiss women of the same age born in Switzerland. Similar proportions were found in the FGS 2018 data: 42 percent of foreign women versus 38 percent of Swiss women in their 40s had an adult child.

Another difficulty when using the STATPOP database is analysing households in which there are two adult women living with children: as there is no registered 
link between parents and their children, which woman might be the biological mother? We discount such cases. The SFSO population numbers are higher for women in their early 20 s than the STATPOP numbers used in our fertility analysis; 20 percent higher for Swiss nationals and 30 percent for foreigners because of these complications. A priori we assume that the women in households that are analysed are representative of all women of that age, but this may not be the case. Because childless women are more mobile, they can miss being registered and so the fertility of younger migrants may be over-estimated. De-registration upon emigration may not take place and so the household register may remain out-ofdate for some time. The downward kink from 2009-2010 in Figure 2, when a change of population data sets took place, is evidence of this possibility.

For the Family and Generation Surveys of 2013 and 2018 the question is how representative they are. The FGS 2018 intentionally over-sampled women with children under the age of 13 , yet applying weights to "boost" the sample of childless women can lead to distortions. Unintentional over-sampling of women with children is a common problem of surveys, as they tend to be at home more often than childless women are (Kreyenfeld et al. 2011).

In our cohort tracking calculations, we estimate the average fertility by age at immigration, emigration and naturalisation. These estimates are prone to bias and may cause over- or under-estimation which are likely to be compounded at older ages. The estimate of fertility at naturalisation is particularly tentative post-2000 and this could have a substantial impact on the final estimates of cohort fertility by nationality.

Taking all these limitations into consideration, it is reassuring that the different data sets point to the same conclusion. Although the fertility of foreign women in their 20s is higher than that of Swiss nationals, by the late 30 s the fertility of Swiss nationals has overtaken that of foreign women. The next section details the processes that cause this crossover to happen.

\section{$7 \quad$ The processes that affect cohort fertility}

This section summarises the differences in behaviour of the sub-groups of population that lead to the fertility patterns seen in the previous section.

1. Foreign women born abroad tend to start childbearing at younger ages than Swiss women born in Switzerland (Fig. 5); hence the fertility of foreign women is higher than that of Swiss women up to the mid-30s (Fig. 9).

2. Swiss women born in Switzerland, after starting childbearing later, have a higher propensity to have a second child after their first and after a shorter duration (Rojas et al. 2018). Hence, Swiss mothers have larger families than mothers of foreign nationality (section 8 and Table 4).

3. The ongoing influx of low fertility (often childless) foreign women in their 30s "dilutes" the average fertility of foreign women at these ages (Tables 2 and 3 ).

4. Foreign women who naturalise have higher fertility than foreign women who do not (section 5.3, section 8, Table 4 and Pecoraro 2012). Naturalisation has 
the biggest impact on the net balance of "incoming" children at higher ages, effectively boosting the fertility of Swiss women and reducing that of foreign women (Table 1).

5. Foreign emigrants have (slightly) higher fertility than foreign immigrants, whereas Swiss nationals have slightly higher fertility at (re-)immigration than Swiss women at emigration (section 5.2 and Table 3 ).

Having described the difference in fertility of Swiss and foreign women across the reproductive life course, and the processes leading to these differentials, we now tackle the question of why the TFR fails to accurately describe the fertility of foreign and immigrant women.

\section{$8 \quad$ The standard TFR and a comparison with cohort fertility measures}

The SFSO publishes the TFR of foreigners together with that of the Swiss population (Fig. 10), describing the TFR in their statistical digest as the "average number of children per woman" (SFSO 2019). Since 2011, the SFSO has also provided the TFR by country of birth and nationality (Table 4). From those published statistics the layman would assume that foreigners - and foreigners born abroad especially have more children than Swiss women do, and considerably more than the "Swiss born in Switzerland". Yet this is misleading. Section 6 of this paper demonstrated that cohorts of women with Swiss nationality older than their mid-30s actually have higher fertility than those of foreign nationality: Section 7 described how this happens.

The TFR of foreign women has been quite stable since 2001, at around 1.87 (Fig. 10), despite changes in their composition (Fig. 2). For Swiss nationals, it rose from a minimum value of 1.22 in 2001-2003 to 1.40 in 2009 and has remained quite stable since. Because women aged 39 (the focus in our analyses) have passed through most of their reproductive life with quite stable age-specific fertility rates then, from a naïve perspective, we could expect the TFR would predict ultimate cohort fertility. However, postponement of childbearing has been steady and ongoing from 1970 until very recently and the associated distortion causes the TFR to under-estimate cohort fertility (Bongaarts/Feeney 1998), deflating the overall TFR of Switzerland by about 0.2 every year.

In addition to the published TFRs, we have also been supplied with data on births by biological birth order. Therefore we can calculate the TFR1 and deduce the fertility of mothers (women who have had at least one child, TFR/TFR1), and the synthetic childlessness rate (1-TFR1) (Table 4). The TFR1, first birth rate, is especially interesting as it points to the main weakness of the standard TFR. For foreign women the TFR1 is higher than one; the subgroup with the highest rate being for the "foreign born abroad", a similar statistical quirk as found by Parrado (2011) for Mexican immigrants to the United States. However, the TFR1 is simply a measure of the intensity of having a first birth, which, as we saw in Figure 7, is particularly high in the years immediately after immigration to Switzerland. 
Fig. 10: The standard TFR for Swiss and foreign women, 1971-2018 Children per woman

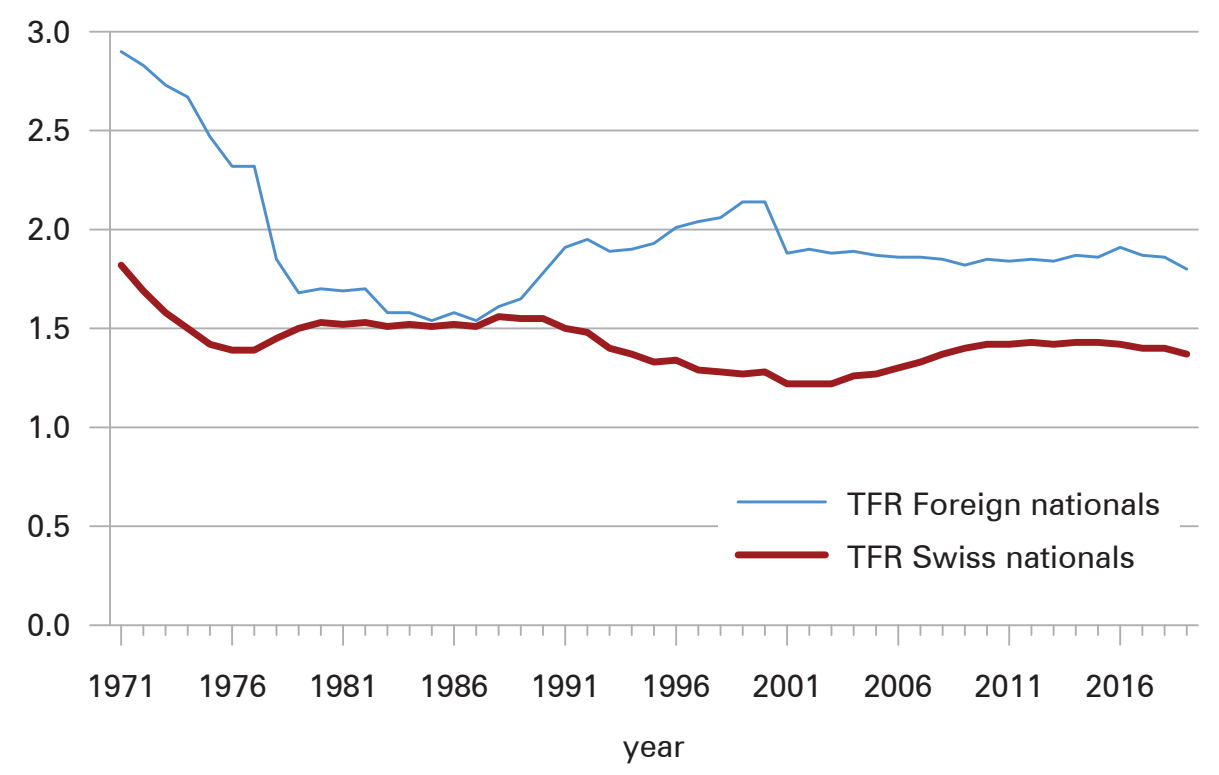

Note: the sharp downward kink in the TFR of foreign women between 2000 and 2001 is because after 2000 births to asylum seekers and other temporary residents were no longer included in the statistics.

Source: SFSO

Table 4 shows the important differences - and also an interesting similarity between the TFR and cohort fertility measures.

First, the differences. The TFR and TFR1 show significantly higher values for foreign women than for Swiss nationals. The TFR for subgroup "Foreign born

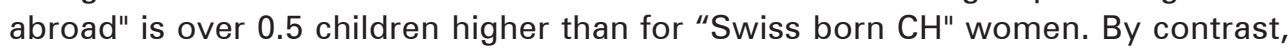
looking at cohort fertility, Swiss women aged about 39 have higher fertility than foreign women by an average of 0.2 children across the four data sets. The subgroup with the highest cohort fertility is "Swiss born abroad", who are mostly naturalised immigrants (as discussed in section 5.3). The fertility of "Foreign born abroad" women is significantly lower: they can be considered mostly to be "pre-naturalised" immigrants.

The childlessness section of Table 4 shows a wide range of values between the two FGS rounds and STATPOP: the difficulties of sampling and registering (and deregistering) childless women were discussed in section 6 . The synthetic childless rate (1-TFR1) gives "impossible" negative values for the "Foreign born abroad" subgroup. For Swiss women, we see the opposite problem: it is excessively high. Both are caused by tempo distortions: postponement deflates the TFR1 whilst the migration tempo effect inflates it. 


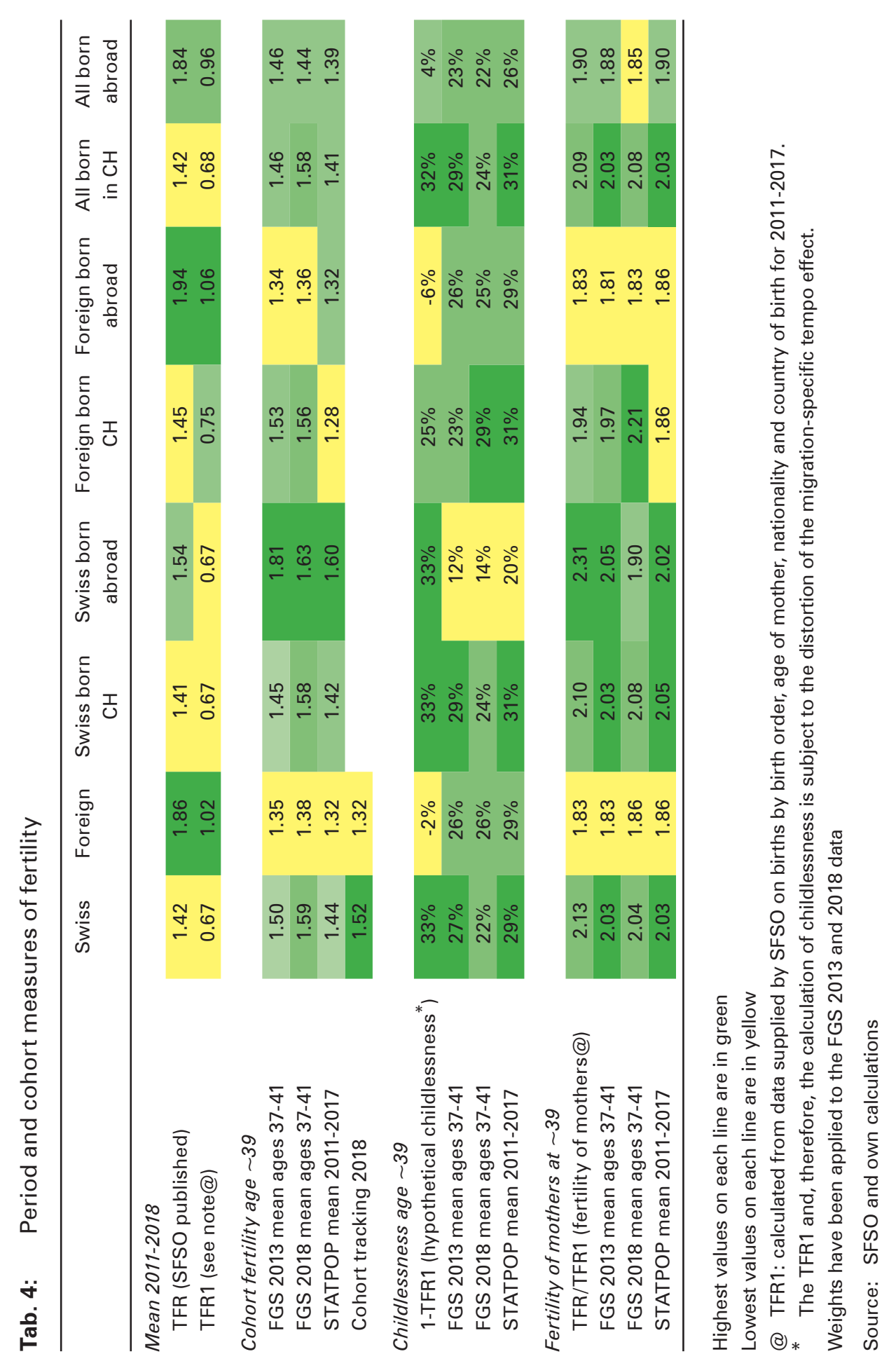


The group with the lowest observed childlessness is the "Swiss born abroad" ("post-naturalised") subgroup, yet their TFR1 is low. The likely explanation is that they commonly have had at least one child by the time they naturalise.

We see remarkable agreement for four different estimates of the "Fertility of mothers"; the synthetic measure (TFR/TFR1) and the three sets of observed values. In each of these cases the number of children of Swiss mothers is higher than of foreign mothers. The subgroup of mothers with the lowest fertility is the "Foreign born abroad" (the "pre-naturalised").

One final observation: the differentials in cohort fertility by country of birth (final two columns) are smaller than between nationality (first two columns). In particular, average cohort fertility at age 39 is very similar for women born either in Switzerland or abroad. However, the fertility of Swiss-born mothers averages 0.16 children higher than for immigrant mothers, the reason being that the latter more often stop after having had one child.

One of the primary weaknesses in calculating the standard TFR is the denominator used in the ASFR calculation, the exposed population. In their country of origin, future migrants are in the denominator during the period when they are often childless; hence the TFR of that country is "deflated". This is the case for any country with strong emigration of young adults, such as the Eastern European countries. It is also the case for Swiss nationals in Switzerland as they have net out-migration throughout their reproductive life course (Fig. 6). By contrast, in the arrival country they are only in the denominator for the most fertile period of their reproductive life (late 20s and early to mid-30s), and so their TFR in the receiving country is "inflated" and the TFR in that country is boosted.

\section{$9 \quad$ Discussion and conclusions}

The purpose of this paper was to elucidate the processes that lead to the completed cohort fertility of women with Swiss nationality being higher than that of foreign nationals, whilst the TFR of foreign women is substantially higher than that of Swiss women. Using a novel methodology that tracks the arrivals and departures of Swiss and foreign women and their children to the "system", we enumerate the relative impact of births, immigration, emigration and naturalisation. This cohort tracking method also bypasses any distortion from postponement, a well-known problem of the standard TFR.

Our findings support studies from other countries showing a high intensity of first births in the years after migration, following low pre-migration fertility $(\mathrm{Ng} /$ Nault 1997; Toulemon/Mazuy 2004; Andersson 2004; Dubuc 2012; Robards/ Berrington 2016; Tønnessen 2020). Our methodology does not take into account the duration of stay in Switzerland, unlike Toulemon and Mazuy (2004). However, like Toulemon and Mazuy and Dubuc $(2009,2012)$ pre-migration fertility is taken into account. The fertility of emigrants is also included in our calculations. We also enumerate the impact of naturalisation on the fertility of foreigners and Swiss nationals, as hypothesized by Sobotka and Lutz (2010). As nationality (Swiss/foreign) 
is the dichotomy employed by the Swiss Statistical Office, it is important to take the significant impact of naturalisation into account.

The impact of foreigner fertility continues to be larger for Switzerland than other European countries (Sobotka 2008). From 2011-2018, it has boosted the overall TFR of the country by an average of 0.11 children per woman annually. The fertility curve by age of foreigners is bi-modal, as described in Burkimsher (2017) and it is the early bulge of women in their 20s that boosts the country's TFR, the cause being the high intensity of births commonly observed in the years following immigration. In several Swiss cantons the number of babies born to foreigners exceeds the number born to Swiss women. However, we wish to underline that this is not because foreigners have larger families than native Swiss. In fact, the opposite is true, as demonstrated in this paper. Berrington and Stone (2017) deplored the problem of the media inciting prejudice by interpreting the higher TFR of immigrants (as published by national statistical offices) as indicating that they have large families. We propose that a better descriptor to publish would be the "fertility of mothers" - TFR/TFR1 - which we have shown corresponds much more closely to the observed cohort fertility of mothers. This measure has the advantage of mitigating the impact of any misestimates of the population and would be easier to implement than trying to correct the TFR for the migration-specific tempo effect (although it would depend on a country recording all births by biological birth order). It is particularly challenging to keep track of the highly mobile childless population, even in a country like Switzerland with a comprehensive household registration system.

The statistics published by the SFSO generally dichotomise between Swiss and foreign nationals. However, the country of birth of the mother would be a more precise basis for comparison, as it does not change through a person's life (Austria and Sweden, for example, do this). We have found that the ultimate (cohort) fertility of women, whether born within or outside Switzerland, is currently quite similar. Childlessness is higher amongst Swiss women, but Swiss mothers have, on average, more children than foreign mothers. The standard TFR fails to describe this reality and can feed into a media narrative of prejudice against foreigners.

\section{Acknowledgements}

The Families and Generations Surveys (FGS) of 2013 and 2018 were carried out by the Swiss Federal Statistical Office (SFSO). Funding for access to the FGS 2013 data and the 2000 census from the SFSO was provided by the Institut de sciences sociales des religions, University of Lausanne. This publication benefited from the support of the Swiss National Centre of Competence in Research LIVES - Overcoming vulnerability: Life course perspectives (NCCR LIVES). Access to the FGS 2018 data was made possible through LIVES. The LIVES project is financed by the Swiss National Science Foundation (grant number: 51NF40- 160590). The authors are grateful to the Swiss National Science Foundation for its financial assistance.

The first version of this paper was published online as a LIVES Working Paper 2018/73 entitled "Who has more children in Switzerland: Swiss or foreign women? Why the TFR is a misleading measure". New data from STATPOP for the years 2015- 
2017 has since become available, as have the results from the FGS 2018, and these have been incorporated into this paper.

\section{References}

Abbasi-Shavazi, Mohammad Jalal; McDonald, Peter 2002: A comparison of fertility patterns of European immigrants in Australia with those in the countries of origin. In: Genus 58,1: 53-76.

Andersson, Gunnar 2004: Childbearing after Migration: Fertility patterns of foreign-born women in Sweden. In: International Migration Review 38,2: 747-774.

Berrington, Ann; Stone, Juliet 2017: Understanding third and fourth births in Britain: What role do increased immigration and multiple partnerships play? ESRC Centre for Population Change Working Paper 83. Southampton.

Bongaarts, John; Feeney, Griffith 1998: On the quantum and tempo of fertility. In: Population and Development Review 24,2: 271-291. https://doi.org/10.2307/2807974

Burkimsher, Marion 2017: Evolution of the shape of the fertility curve: Why might some countries develop a bimodal curve? In: Demographic Research 37,11: 295-324. https://doi.org/10.4054/DemRes.2017.37.11

Burkimsher, Marion; Rossier, Clémentine 2017: Foreigners in Switzerland boost the country's fertility rate, yet they now have smaller families than native Swiss: how so? Paper presented at the Workshop on the Fertility of Migrants and Minorities. Leibnitz University, Hanover, February 2017 [https://www.researchgate.net/ publication/313475699_Foreigners_in_Switzerland_boost_the_country's_fertility rate_yet_they_now_have_smaller_families_than_native_Swiss_how_so, 12. $\overline{1} 2.2020]$.

Burkimsher, Marion; Zeman, Kryštof 2017: Childlessness in Switzerland and Austria. In: Kreyenfeld, Michaela; Konietzka, Dirk (Eds.): Childlessness in Europe: Contexts, Causes, and Consequences. Cham, Switzerland: Springer: 115-137. https://doi.org/10.1007/978-3-319-44667-7_6

Calot, Gérard 1998: Two centuries of Swiss demographic history: graphic album of the 1860-2050 period. Swiss Federal Statistical Office: Neuchâtel.

Cho, Lee-Jay; Retherford, Robert D.; Choe, Minja Kim 1986: The own-children method of fertility estimation. Honolulu, Hawaii: University of Hawaii Press.

D’Amato, Gianni; Wanner, Philippe; Steiner, Ilka 2019: Today's Migration-Mobility nexus in Switzerland. In: Steiner, Ilka; Wanner, Philippe (Eds.): Migrants and Expats: The Swiss Migration and Mobility Nexus. IMISCOE Research Series. Cham: Springer: 3-20. https://doi.org/10.1007/978-3-030-05671-1_1

Dubuc, Sylvie 2009: Application of the Own-Children Method for estimating fertility by ethnic and religious groups in the UK. In: Journal of Population Research 26,3: 207225. https://doi.org/10.1007/s12546-009-9020-7

Dubuc, Sylvie 2012: Immigration to the UK from high-fertility countries: intergenerational adaptation and fertility convergence. In: Population and Development Review 38,2: 353-68.

Dubuc, Sy/vie 2016: Immigrants and ethnic fertility convergence. In: Champion, Tony; Falkingham, Jane (Eds.): Population change in the United Kingdom. Rowman \& Littlefield International Editions: 65-84.

Eurostat 2020: Share of non-nationals in the resident population [https://ec.europa.eu/ eurostat/web/products-eurostat-news/-/DDN-20190315-1, 29.09.2020]. 
Gerber, Roxane; Burkimsher, Marion (forthcoming): Familles migrantes: différences de calendrier et défis face aux difficultés de conciliation travail-famille. In: Rossier, Clémentine; Sauvain-Dugerdil, Claudine; Bernardi, Laura (Eds.): Diversité des familles et bien-être en Suisse. Lausanne: Editions Seismo.

Impicciatore, Roberto; Gabrielli, Giuseppe; Paterno, Anna 2020: Migrants' Fertility in Italy: A Comparison Between Origin and Destination. In: European Journal of Population 36: 799-825. https://doi.org/10.1007/s10680-019-09553-w

Krapf, Sandra; Kreyenfeld, Michaela 2015: Fertility Assessment with the Own-ChildrenMethod: A Validation with Data from the German Mikrozensus. MPIDR Technical Report 2015-003. Rostock: Max Planck Institute for Demographic Research.

Kreyenfeld, Michaela; Zeman, Kryštof; Burkimsher, Marion; Jaschinski, Ina 2011: Fertility data for German speaking countries: What is the potential? Where are the pitfalls? In: Comparative Population Studies 36,2-3: 349-38. https://doi.org/10.4232/10.CPoS-2011-06en

Milewski, Nadja 2010: Immigrant fertility in West Germany: Is there a socialization effect in transitions to second and third births? In: European Journal of Population/Revue européenne de Démographie 26,3: 297-323. https://doi.org/10.1007/s10680-010-9211-0

NCCR on the move 2018: The Migration-Mobility Survey. National Center of Competence in Research, The Migration-Mobility Nexus [https://nccr-onthemove.ch/research/ migration-mobility-survey/, 24.11.2020].

Ng, Edward; Nault, François 1997: Fertility among recent immigrant women to Canada 1991: An examination of the disruption hypothesis. In: International Migration 35,4: 559-580. https://doi.org/10.1111/1468-2435.00027

Parrado, Emilio A. 2011: How high is Hispanic/Mexican fertility in the United states? Immigration and tempo considerations. In: Demography 48,3: 1059-1080. https://doi.org/10.1007/s13524-011-0045-0

Pecoraro, Marco 2012: Devenir Suisse: les facteurs intervenant dans le choix de se naturaliser. In: Wanner, Philippe et al.: La démographie des étrangers en Suisse. Zürich/Geneva: Seismo.

Robards, James; Berrington, Ann 2016: The fertility of recent migrants to England and Wales. In: Demographic Research 34,36: 1037-1052. https://doi.org/10.4054/DemRes.2016.34.36

Rojas, Eder Andres Guarin; Bernardi, Laura; Schmid, Flurina 2018: First and second births among immigrants and their descendants in Switzerland. In: Demographic Research 38,11: 247-286. https://doi.org/10.4054/DemRes.2018.38.11

Ruckdeschel, Kerstin et al. 2018: Unequal Neighbours? A French-German Comparison of Family Size Intentions. Comparative Population Studies 43: 187-210. https://doi.org/10.12765/CPoS-2018-12en

SEM (Secrétariat d'État aux migrations) 2018: Naturalisation ordinaire [https://www. sem.admin.ch/sem/fr/home/themen/buergerrecht/einbuergerung/ordentliche einbuergerung.html, 13.03.2020].

SFSO (Swiss Federal Statistical Office) 2013: Families and Generations Survey factsheet [https://www.bfs.admin.ch/bfsstatic/dam/assets/4082634/master, 12.12.2020].

SFSO (Swiss Federal Statistical Office) 2016a: Population and Households Statistics (STATPOP) factsheet [https://www.bfs.admin.ch/bfsstatic/dam/assets/8541/master, 12.12.2020]. 
SFSO (Swiss Federal Statistical Office) 2016b: Statistique de la population résidante de nationalité étrangère (1991-2009) [https://www.bfs.admin.ch/bfsstatic/dam/ assets/6809/master, 12.12.2020].

SFSO (Swiss Federal Statistical Office) 2019: Statistical Data on Switzerland 2019. Annual booklet published by the Federal Statistical Office, Neuchâtel.

Sobotka, Tomáš 2008: Overview Chapter 7: The rising importance of migrants for childbearing in Europe. In: Demographic Research 19,9: 225-248. https://doi.org/10.4054/DemRes.2008.19.9

Sobotka, Tomáš; Lutz, Wolfgang 2010: Misleading policy messages derived from the period TFR: Should we stop using it? In: Comparative Population Studies 35,3: 637 664. https://doi.org/10.4232/10.CPoS-2010-15en

Steiner, Ilka; Wanner, Philippe (Eds.) 2019: Migrants and Expats: The Swiss Migration and Mobility Nexus. IMISCOE Research Series. Cham: Springer https://doi.org/10.1007/978-3-030-05671-1

Swiss/nfo 2007: German citizenship law to boost Swiss expats [https://www.swissinfo. ch/eng/german-citizenship-law-to-boost-swiss-expats/6084376, 29.09.2020].

Swiss/nfo 2018: Becoming a citizen [https://www.swissinfo.ch/eng/becoming-acitizen/29288376, 29.09.2020].

Tønnessen, Marianne 2020: Declined Total Fertility Rate Among Immigrants and the Role of Newly Arrived Women in Norway. In: European Journal of Population 36: 547 573. https://doi.org/10.1007/s10680-019-09541-0

Toulemon, Laurent; Mazuy, Magali 2004: Comment prendre en compte l'âge à l'arrivée et la durée du séjour en France dans la mesure de la fécondité des immigrants. Working paper 120. INED.

Wanner, Philippe 2002: The demographic characteristics of immigrant populations in Switzerland. In: Haug, Werner; Compton, Paul; Courbage, Youssef (Eds.): The demographic characteristics of immigrant populations (Population studies No. 38). Council of Europe: 419-496.

Wanner, Philippe; Fei, Peng 2005: Facteurs influençant le comportement reproductifs des Suissesses et des Suisses. Office fédéral de la statistique: Neuchâtel.

Wanner, Philippe et al. 2012: La démographie des étrangers en Suisse. Zürich/Geneva: Seismo.

Marion Burkimsher, PhD ( $\varangle)$. University of Lausanne. Lausanne, Switzerland. E-mail: drmarionb@gmail.com, URL: http://drmarionb.free.fr/resume

Clémentine Rossier. Associate Professor. Prof. Philippe Wanner. University of Geneva. Geneva, Switzerland. E-mail: clementine.rossier@unige.ch,Philippe.Wanner@unige.ch

URL: https://www.unige.ch/sciences-societe/ideso/membres/rossier/ https://www.unige.ch/sciences-societe/ideso/membres/wanner/ 


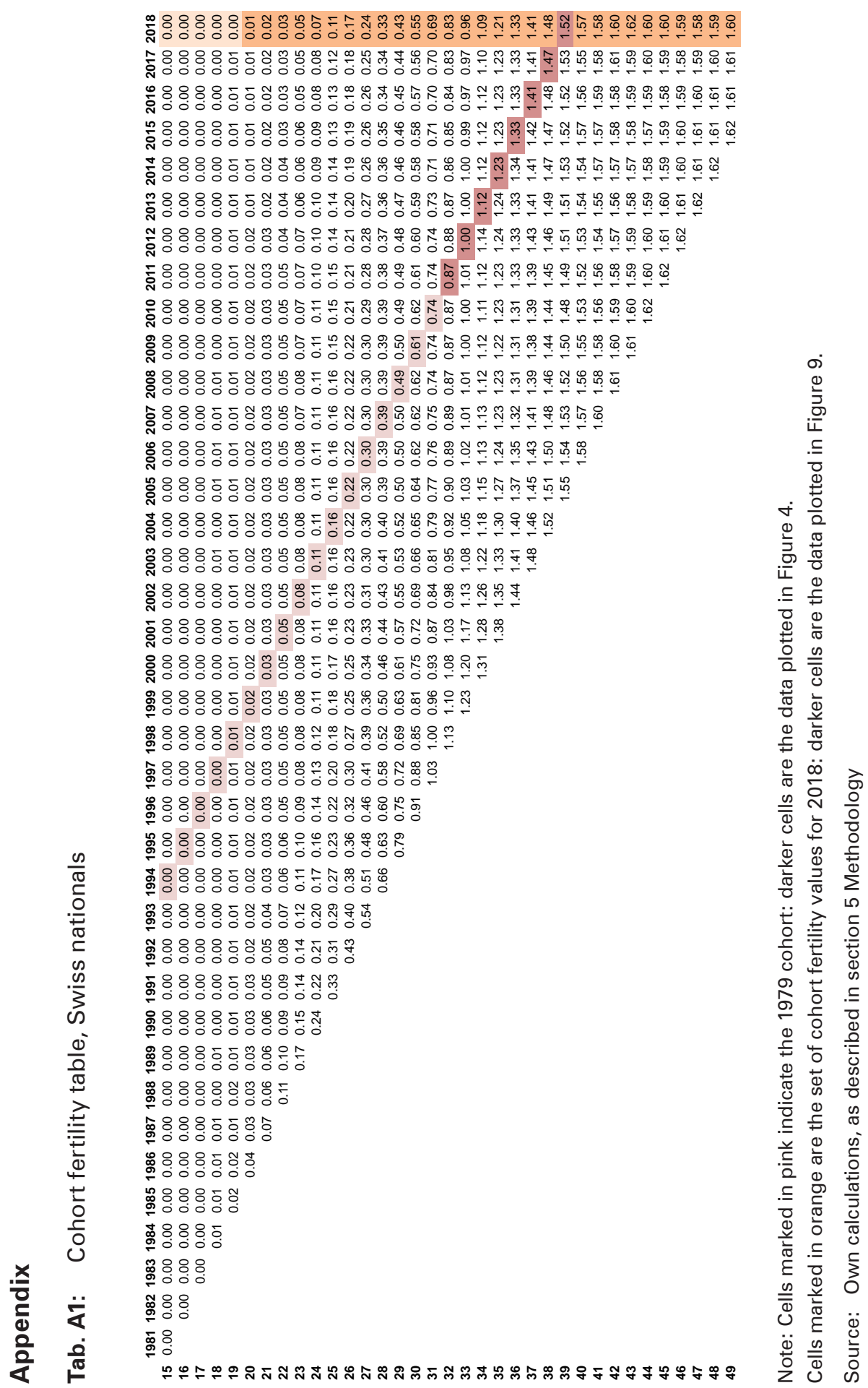




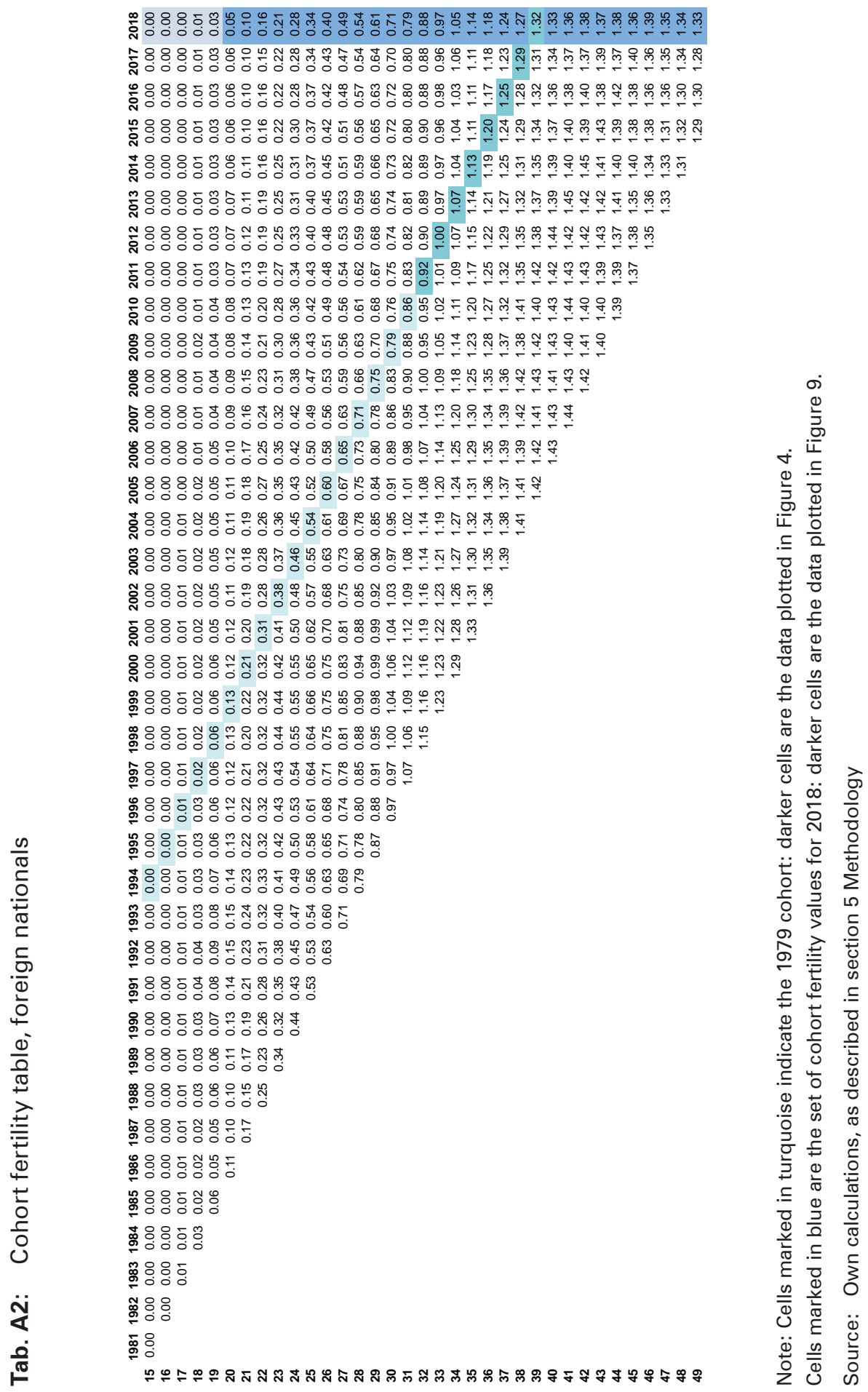




\section{Comparative Population Studies}

WWW.comparativepopulationstudies.de

ISSN: 1869-8980 (Print) - 1869-8999 (Internet)

\section{Published by}

Prof. Dr. Norbert F. Schneider

Federal Institute for Population Research D-65180 Wiesbaden / Germany

\section{(cc) BY-SA}

2020

\section{Managing Editor}

Prof. Dr. Johannes Huinink

Dr. Katrin Schiefer

\section{Editorial Assistant}

Beatriz Feiler-Fuchs

Wiebke Hamann

\section{Layout}

Beatriz Feiler-Fuchs

E-mail:cpos@bib.bund.de

\section{Scientific Advisory Board}

Karsten Hank (Cologne)

Michaela Kreyenfeld (Berlin)

Marc Luy (Vienna)

Natalie Nitsche (Rostock)

Zsolt Spéder (Budapest)

Rainer Wehrhahn (Kiel)

\section{Board of Reviewers}

Bruno Arpino (Barcelona)

Kieron Barclay (Rostock)

Laura Bernardi (Lausanne)

Gabriele Doblhammer (Rostock)

Anette Eva Fasang (Berlin)

Michael Feldhaus (Oldenburg)

Tomas Frejka (Sanibel)

Alexia Fürnkranz-Prskawetz (Vienna)

Birgit Glorius (Chemnitz)

Fanny Janssen (Groningen)

Frank Kalter (Mannheim)

Stefanie Kley (Hamburg)

Bernhard Köppen (Koblenz)

Anne-Kristin Kuhnt (Duisburg)

Hill Kulu (St Andrews)

Nadja Milewski (Rostock)

Roland Rau (Rostock)

Thorsten Schneider (Leipzig)

Tomas Sobotka (Vienna)

Jeroen J. A. Spijker (Barcelona)

Heike Trappe (Rostock)

Helga de Valk (The Hague)

Sergi Vidal (Barcelona)

Michael Wagner (Cologne) 